\title{
Uncertainty of Hydrological Model Components in Climate Change Studies over Two Nordic Quebec Catchments ${ }^{\mathscr{C}}$
}

\author{
MAgALi TROIN \\ Department of Construction Engineering, École de technologie supérieure, Université du Québec, Montreal, Quebec, Canada \\ RICHARD ARSENAULT \\ Department of Construction Engineering, École de technologie supérieure, Université du Québec, Montreal, and Rio Tinto, \\ Quebec Power Operations, Jonquière, Québec, Canada \\ JEAN-LUC MARTEL AND FRANÇOIS BRISSETTE \\ Department of Construction Engineering, École de technologie supérieure, Université du Québec, Montreal, Quebec, Canada
}

(Manuscript received 5 January 2017, in final form 20 October 2017)

\begin{abstract}
Projected climate change effects on hydrology are investigated for the 2041-60 horizon under the A2 emission scenarios using a multimodel approach over two snowmelt-dominated catchments in Canada. An ensemble of 105 members was obtained by combining seven snow models (SMs), five potential evapotranspiration (PET) methods, and three hydrological model (HM) structures. The study was performed using highresolution simulations from the Canadian Regional Climate Model (CRCM-15 km) driven by two members of the third-generation Canadian Coupled Global Climate Model (CGCM3). This study aims to compare various combinations of SM-PET-HM in terms of their ability to simulate streamflows under the current climate and to evaluate how they affect the assessment of the climate change-induced hydrological impacts at the catchment scale. The variability of streamflow response caused by the use of different SMs (degree-day versus degree-day/energy balance), PET methods (temperature-based versus radiation-based methods), and HM structures is evaluated, as well as the uncertainty due to the natural climate variability (CRCM intermember variability). The hydroclimatic simulations cover 1961-90 in the present period and 2041-60 in the future period. The ensemble spread of the climate change signal on streamflow is large and varies with catchments. Using the variance decomposition on three hydrologic indicators, the HM structure was found to make the most substantial contribution to uncertainty, followed by the choice of the PET methods or natural climate variability, depending on the hydrologic indicator and the catchment. Snow models played a minor, almost negligible role in the assessment of the climate change impacts on streamflow for the study catchments.
\end{abstract}

\section{Introduction}

There is an increasing interest in impact studies for future climate projections and the impacts on hydrological systems in order to identify suitable strategies for adaptation and mitigation. Considering uncertainty is an essential step in climate change impact studies, since the value of a hydrologic projection can be restricted

Supplemental information related to this paper is available at the Journals Online website: https://doi.org/10.1175/ JHM-D-17-0002.s1.

Corresponding author: Magali Troin, troin.magali@ouranos.ca without an adequate evaluation of associated uncertainty (Georgakakos et al. 2004; Wagener and Gupta 2005). To provide a complete uncertainty analysis on hydrological projections, five sources of uncertainty need to be explored throughout the modeling process: 1 ) emission scenarios, 2) global climate model (GCM), 3) natural variability of climate, 4) downscaling method, and 5) hydrological model (Wilby and Harris 2006). Uncertainties of emission scenario, climate model projection (e.g., Giorgi and Mearns 2002; Tebaldi et al. 2005; Jung and Chang 2011; Bae et al. 2011; Hawkins and Sutton 2009, 2011), and downscaling method (e.g., Fowler et al. 2007; Chen et al. 2011a; Troin et al. 2015a) have been intensively analyzed in recent studies; they 
are generally accepted as being the most important sources of uncertainty (Prudhomme and Davies 2009a, b; Kay et al. 2009; Chen et al. 2011b). Natural climate variability (Peixoto and Oort 1992; McGuffie and Henderson-Sellers 2005) could also have a significant effect on the total uncertainty, especially at the catchment scale (e.g., Hawkins et al. 2009, 2011; Deser et al. 2012a,b; de Elía et al. 2013; Fatichi et al. 2014; Thompson et al. 2015; Haque et al. 2015; Seaby et al. 2015; Troin et al. 2016). The uncertainty associated with hydrological modeling can also be significant and should be assessed when quantitative hydrologic projections of climate change impacts are expected; a robust characterization of uncertainty is also a critical and challenging issue for operational hydrologic forecasting (Liu and Gupta 2007; Van Griensven et al. 2008; Sudheer et al. 2011; Arsenault and Brissette 2016).

To assess hydrological modeling uncertainty, two major sources need to be explored under stationary climate conditions: 1) model parameters describing the difficulty in attributing exact parameter values because of finite lengths and uncertainty in the calibration data, an imperfect understanding of process and approximations; and 2) model structure, referred to as "model uncertainty," due to the lumped and simplified representation of hydrological processes (Lindenschmidt et al. 2007; Renard et al. 2010). Additional uncertainties can be considered under nonstationary climate conditions (changing climatic conditions), stemming from instability of parameters because of variations in both catchment characteristics and main hydrological processes (Brigode et al. 2013). Wilby (2005) showed that the uncertainty of the nonuniqueness of parameters affects the representation of climate change signals on streamflows. Other authors reported the strong influences of the model structure, with substantial intermodel differences on projected streamflows (e.g., Vano et al. 2015; Mendoza et al. 2015; Velázquez et al. 2015a). When both sources are compared to each other, the model structure uncertainty remains the greatest one under stationary and nonstationary climate conditions (Najafi et al. 2011; Poulin et al. 2011; Fu et al. 2015). The characterization and reduction of uncertainties are thus challenging in the hydrological modeling field (Clark et al. 2016). The understanding of these uncertainties is still incomplete, and dedicated research is needed to substantially reduce model uncertainty.

Many components structure a hydrological model (HM); each component brings an uncertainty, contributing to the total uncertainty of the model structure. The uncertainties of the most sensitive components of nonstationary climate conditions must be examined in order to provide reliable streamflow projections. The most sensitive components of nonstationary climate conditions include snow models (SMs) and potential evapotranspiration (PET) computation methods. In a recent work, Troin et al. (2016) made an attempt to estimate the uncertainty on snow water equivalent projections related to the type of SM by using an ensemble of eight degree-day (DD) and mixed degree-day/energy balance (DD/EB) SMs. The authors concluded that both types of SMs lead to similar snow water equivalent projections at the basin scale. This study confirmed the results of Troin et al. (2015b), where, using the same ensemble of SMs, a low level of SM uncertainty in simulating snowmelt flows is found under the current climate. Bae et al. (2011) explored the impacts of three HMs with PET-related computation methods on streamflow projections. The authors showed that the PET methods have contrasted sensitivities to climate projections, resulting in a large spread of projected runoff changes at the catchment scale. A key research effort toward the reduction of model structure uncertainty therefore aims to better characterize the uncertainty derived from each main HM component by using adequate modeling frameworks. Recent studies focusing on the analysis of model uncertainties have highlighted that the multimodel strategy is a skillful pathway to explore the associated uncertainties to hydrological projections resulting from models (e.g., Ajami et al. 2006; Duan et al. 2007; Bohn et al. 2010; Velázquez et al. 2011). Comparing SM, PET method, and HM structure multicombinations and showing how the combinations of these multimodel components can affect streamflow projections could improve the knowledge of model structure uncertainty.

The aim of this study is to evaluate different types of SM-PET-HM combinations, by taking into account uncertainties from the SMs (DD versus DD/EB models), the PET methods (temperature-based versus radiationbased methods), and the HM structures. The multimodel approach is composed of 105 combinations of SM-PET-HM. The ensemble is implemented over two typical catchments in Quebec, Canada, in terms of land cover types and Nordic climates. The Arnaud basin is located in the Nunavik region, northern Quebec, and the Mistassini basin is situated in the Saguenay-Lac-SaintJean region in central Quebec. Figure 1 shows the location of each basin, and Table 1 lists some general characteristics. For the two catchments, daily climate data came from the high-resolution simulations ensemble of the Canadian Regional Climate Model (CRCM-15 km) driven by the third-generation Canadian Coupled Global Climate Model (CGCM3). The CRCM simulations feed 


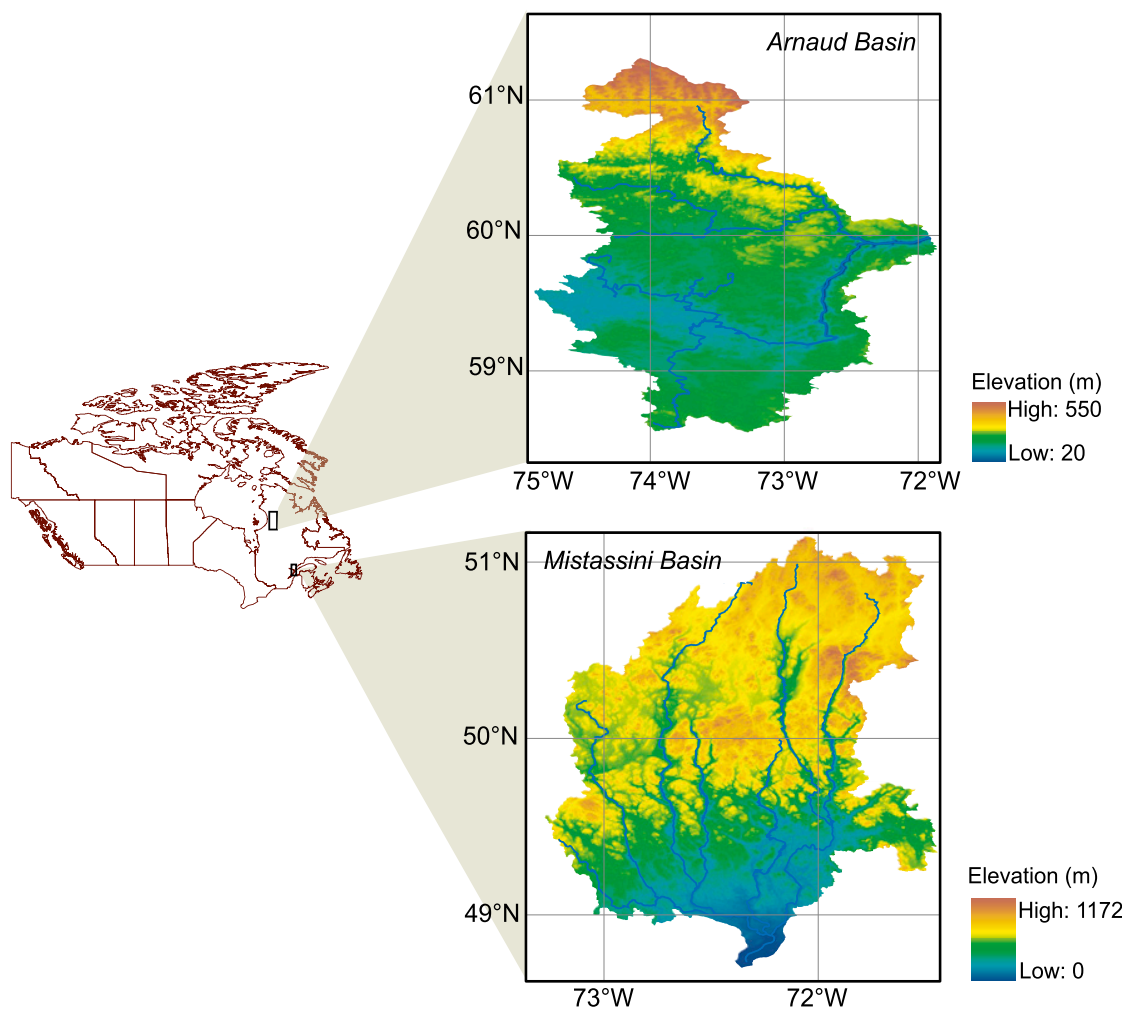

FIG. 1. Location map of the study basins.

the multimodels to simulate the catchments' hydrology. The evaluation is made under current (1961-90) and future (2041-60) climates by evaluating the differences between the hydrological simulations and the CRCM pseudo-observations in the virtual world. More information is given in section $2 b$. The virtual world provides a complete database without missing data or space and time incoherencies (Maraun 2012; Arsenault and Brissette 2014; Velázquez et al. 2015b; Arsenault and Brissette 2016; Troin et al. 2016). In addition to the decreasing of uncertainties due to the nonexistence and/ or shortcomings of the meteorological time series in the real world over the study basins (e.g., solar radiation, snow albedo, surface pressure), this approach provides hydrologic projections under climate change conditions. The CRCM simulations used in this work allow the uncertainty of the natural variability of climate to be explored and then compared to hydrological model uncertainty. Additional uncertainties related to the RCMs (e.g., scenario and intermodel variability) cannot be evaluated with this ensemble, since it rests on a single scenario and regional model.

In the following, the CRCM ensemble and the virtual world concept are presented in section 2. Section 3 describes the multimodel approach. In section 4 , the results from the multimodel approach are analyzed for the historical and future periods. Section 5 discusses the uncertainties of the model components and the natural climate variability on the streamflow projections. Concluding comments are provided in section 6 .

TABLE 1. General characteristics of the study basins.

\begin{tabular}{lcc}
\hline \hline & \multicolumn{2}{c}{ Basins } \\
\cline { 2 - 3 } & Mistassini & Arnaud \\
\hline Drainage area ${ }^{\mathrm{a}}\left(\mathrm{km}^{2}\right)$ & 11250 & 26775 \\
Elevation range $(\mathrm{m})$ & $120-700$ & $22-547$ \\
Main land cover type & Forest $(90 \%)$ & Tundra $(90 \%)$ \\
Hydrology: Virtual world & & \\
$\quad$ Mean daily discharge $\left(\mathrm{m}^{3} \mathrm{~s}^{-1}\right)$ & 198 & 204 \\
$\quad$ Annual maximum snow water & 215 & 171 \\
$\quad$ equivalent $(\mathrm{mm})$ & & \\
$\quad$ Annual average actual & 395 & \\
$\quad$ evaporation flux (mm) & & 409 \\
Climate: Virtual world & & \\
$\quad$ Annual average precipitation & 960 & -56.8 \\
$\quad$ total (mm) & & +29.4 \\
$\quad$ Annual daily temperature $\left({ }^{\circ} \mathrm{C}\right)$ & & \\
$\quad$ Min & -51.5 & 119 \\
$\quad$ Max & +34.0 & \\
$\quad$ Mean & -2.5 & \\
Number of grid points & & \\
$\quad$ CRCM (15 km) & 50 &
\end{tabular}

${ }^{a}$ The reported basin surface areas are based on the streamflow gauge position and not on the basin outlet. 


\section{Experimental setup}

\section{a. RCM simulations}

In the present study, we used CRCM version 4.2.4, with a 15-km high-resolution horizontal gridpoint spacing (Caya and Laprise 1999; Laprise et al. 2003; Plummer et al. 2006). Its domain $(225 \times 225$ grid points $)$ is focused over the province of Quebec, which dictates the selection of the basins to this geographical area. Energy and water exchanges between the surface and the atmosphere are simulated by the Canadian Land Surface Scheme, version 2.7 (CLASS 2.7; Verseghy et al. 1993). Snow cover and vegetation canopy are considered in CLASS (Verseghy 1991; Verseghy et al. 1993). An evaluation of the RCM-modeled water cycle can be found in Music and Caya (2007). Additional information about the simulated snow features by CLASS is provided in Langlois et al. (2004, 2014).

\section{$b$. The virtual world principle}

The analysis is performed in the virtual world based upon the CRCM simulations forced at the lateral boundary by a two-member ensemble of the thirdgeneration Canadian Centre for Climate Modelling and Analysis (CCCma) Coupled Global Climate Model (CGCM3.1v2; Flato and Boer 2001). The CRCM simulations are from an older experiment, where the driving CGCM was driven by the strongest A2 emissions scenario during the twenty-first century. Nevertheless, regarding the recent literature on comparisons of climate change signals in the third and fifth phases of the Coupled Model Intercomparison Project (CMIP3 and CMIP5), several studies have reported quite similar trends in projections of future climate between both ensembles (e.g., Lutz et al. 2013; Supharatid 2015; Woldemeskel et al. 2016). The virtual world rests on the principle that the CRCM simulations are considered as pseudo-observations for both the historical and future periods (Troin et al. 2016). The daily climate variables extracted from the CRCM simulations are maximum and minimum temperatures, precipitation, snow albedo, incoming shortwave radiation, wind vectors at $10-\mathrm{m}$ height, screen-specific humidity, and surface pressure.

The pseudo-observed streamflow, on the other hand, is not directly available in the CRCM outputs. Indeed, the climate model simulates overland and below-ground runoffs in the land surface scheme for each grid cell, but excess water is simply removed from the water column at each time step rather than being routed to a river as streamflow. A method was devised by Arsenault and Brissette (2014) to transform distributed runoffs into outlet streamflows. The streamflow generation is carried out in the following three general steps. The first step is to separate the catchment into grids and classify them into zones of influence defined as the distance to the outlet of the basin. This ensures that the routing scheme takes transit time into account on larger basins. Larger basins are awarded more zones than smaller ones. The second step is to average the runoff values of all grid points inside each zone, to require a single averaged value of surface runoff and below-ground runoff per zone. Finally, the unit hydrograph parameters are calibrated using the interannual observed and reconstructed hydrographs on the reference period. Even though the day-to-day representation of discharge from the model and the associated routing scheme is biased by the generation process, the approach allows for comparative analyses as is conducted in current conditions. The routing scheme is applied to generate the daily pseudo-observed flows in both the historical (1961-90) and future (2041-60) periods. Readers can refer to Arsenault and Brissette (2014) for a more detailed methodology.

The advantages of working within a virtual setting were put to use in various recent studies. This method was successfully applied in regionalization method analysis, where regionalization approaches limitations and process uncertainties were quantified (Arsenault and Brissette 2016). It was also used to determine the optimal rain gauge observation network density in datasparse regions (Arsenault and Brissette 2014). Furthermore, Minville et al. (2014) calibrated the HM with observed data and conditioned the evapotranspiration (ET) values to the CRCM-ET values. The skill of the HM was significantly improved. The extreme flooding event in the Richelieu River basin on the U.S.-Canada border in 2011 has been remarkably well modeled by two RCMs driven by ERA-Interim data (Lucas-Picher et al. 2015). These studies indicate that the RCM simulations can convey important information where no measurements exist. Finally, Beauchamp et al. (2013) used the virtual setting to calculate new maximum probable precipitation and flood values, which compare favorably with existing methods. There is thus a growing interest in using virtual laboratories to improve process simulation and reduce uncertainty.

\section{The multimodel pathway}

The procedure to assess the hydrologic uncertainty of model components in streamflow projections using different SM-PET-HM combinations is shown in Fig. 2. The multimodel pathway requires coupling seven snow models with five PET computation methods through three HMs in view of obtaining 105 discharge simulations per catchment over the historical and future 


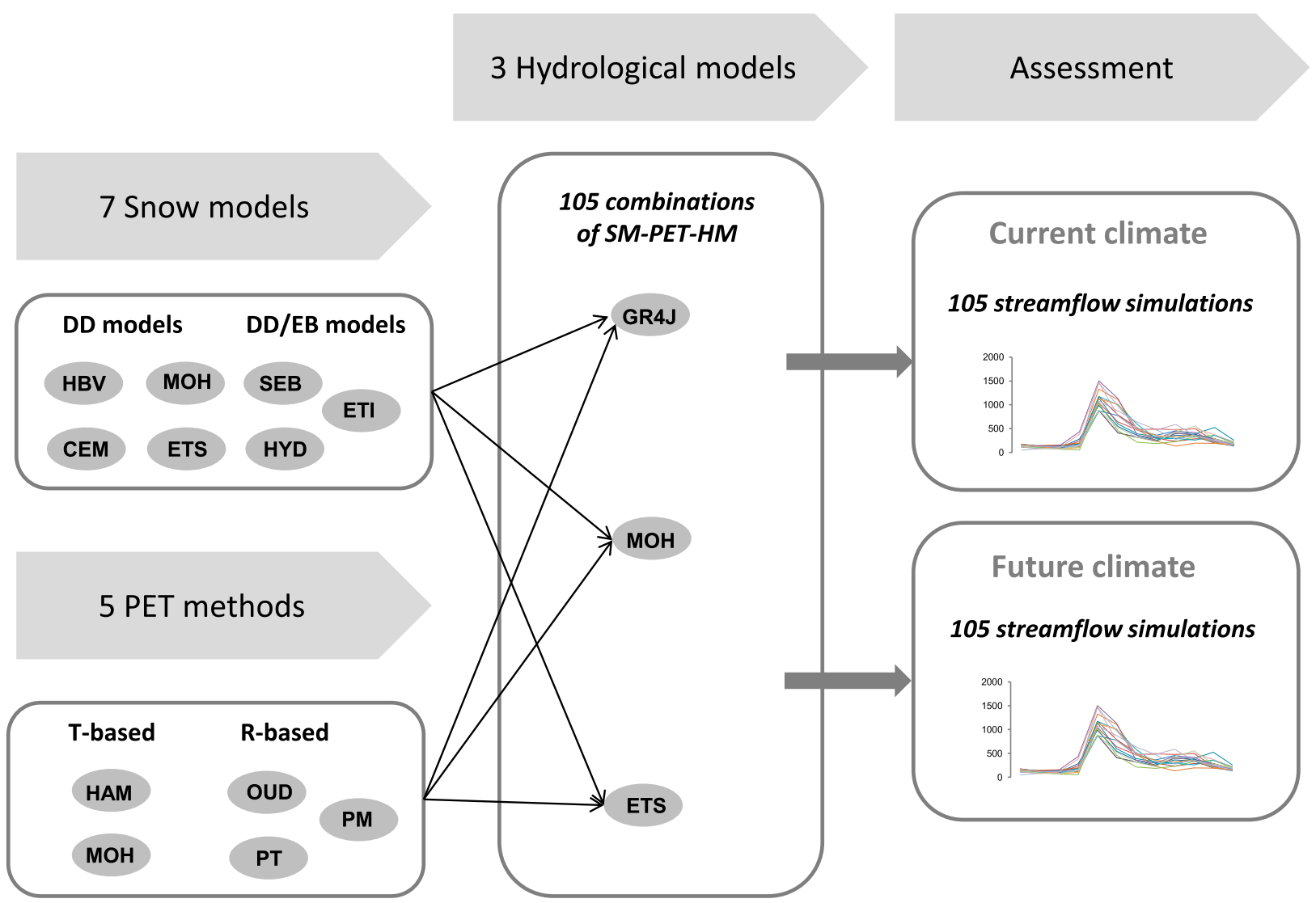

FIG. 2. Schematic description of the multimodel approach conducted per catchment in this study.

periods. In the following, each model component is briefly presented.

\section{a. Snow models description}

In the present study, we compare four SMs derived from the Hydrologiska Byråns Vattenbalansavdelning (HBV), Modèle Hydrologique Simplifié à l'Extrême (MOHYSE), Hydrological Model of Ecole de technologie supérieure (HMETS), and HYDROTEL HMs and three extra SMs [CEMANEIGE, Simplified Energy Balance (SEB), and enhanced temperature index (ETI)]. The seven SMs are grouped into DD (HBV, MOHYSE,
CEMANEIGE, and HMETS) and DD/EB models (HYDROTEL, ETI, and SEB). The discrepancies between the seven SMs are listed in Table 2. The algorithms linked to the snowmelt routines are described in sections $3 \mathrm{a}(1)$ and $3 \mathrm{a}(2)$. A more detailed presentation of the SMs is found in Troin et al. (2016).

\section{1) DD MODELS}

(i) $H B V$

The SM derived from $\mathrm{HBV}($ Bergström 1976) is a simple model based on a temperature index. If the mean

TABLE 2. Conceptual differences between SM model components The acronyms of models and methods used in this study are also specified; $T=$ temperature, $P=$ precipitation amount (liquid and/or solid), ISR $=$ incoming shortwave radiation, and $\alpha=$ snow albedo.

\begin{tabular}{lcccl}
\hline \multicolumn{1}{c}{ Snow models } & Model type & Input data & Snow parameters & \multicolumn{1}{c}{ References } \\
\hline MOHYSE (MOH) & DD & $T, P$ & 2 & Fortin and Turcotte (2007) \\
HBV (HBV) & DD & $T, P$ & 3 & Bergström (1976) \\
CEMANEIGE (CEM) & DD & $T, P$ & 2 & Valéry (2010) \\
HMETS (ETS) & DD & $T, P$ & 10 & Vehviläinen (1992) \\
HYDROTEL (HYD) & DD/EB & $T, P$ & 5 & Turcotte et al. (2007) \\
SEB (SEB) & DD/EB & $T, P$, ISR, $\alpha$ & 2 & Machguth et al. (2006) \\
ETI (ETI) & DD/EB & $T, P$, ISR, $\alpha$ & 2 & Pellicciotti et al. (2005) \\
\hline
\end{tabular}


daily air temperature $T$ is above the threshold value $T_{s}$, snowmelt begins following this equation:

$$
\text { SNOWMELT }=\left(T-T_{s}\right) \times c_{f},
$$

where SNOWMELT is the snowmelt (mm of water), $c_{f}$ is the factor of melt $\left(\mathrm{mm}^{\circ} \mathrm{C}^{-1} \mathrm{day}^{-1}\right), T$ is the mean air temperature $\left({ }^{\circ} \mathrm{C}\right)$, and $T_{s}$ is a threshold temperature value $\left({ }^{\circ} \mathrm{C}\right)$.

\section{(ii) MOHYSE}

The MOHYSE SM is based upon a DD relation (Fortin and Turcotte 2007). The snowpack's mass balance is calculated as

$$
\text { SWE }=\text { SNOW }+ \text { WE_SNOWMELT, }
$$

with

WE_SNOWMELT $=\min \left[c_{f} \times \max \left(T-T_{s}, 0\right), \mathrm{SWE}\right]$,

where SWE is the snowpack's snow water equivalent (mm of water), SNOW is the water equivalent of snow precipitation ( $\mathrm{mm}$ of water), and WE_SNOWMELT is the snowmelt's water equivalent ( $\mathrm{mm}$ of water).

\section{(iii) HMETS}

The DD-based HMETS SM comes from the study of Vehviläinen (1992). The potential snowmelt (pSNOWMELT) is computed as

$$
\begin{aligned}
\operatorname{pSNOWMELT}= & \max \left[0, \operatorname{ddf} \times\left(T-T_{\mathrm{bm}}\right)\right] \\
& \text { if } \quad T>T_{\mathrm{bm}},
\end{aligned}
$$

with

$$
\mathrm{ddf}=\mathrm{ddf}_{\min } \times\left(1+k_{\text {cum }} \times \mathrm{CSM}\right),
$$

where ddf is a factor ranging between a minimum $\left(\mathrm{ddf}_{\min }\right)$ and a maximal value that is a function of the snowmelt cumulative amount $\left(\mathrm{CSM} ; \mathrm{mm}^{\circ} \mathrm{C}^{-1}\right), T_{\mathrm{bm}}$ is the base melting temperature $\left({ }^{\circ} \mathrm{C}\right), k_{\text {cum }}$ is an empirical parameter $\left(\mathrm{mm}^{-1}\right.$ of water), and CSM is the snowmelt cumulative amount ( $\mathrm{mm}$ of water).

\section{(iv) CEMANEIGE}

The SM derived from CEMANEIGE is a complex version of the MOHYSE SM, where the simulation of the snowpack dynamic is improved (Valéry 2010). The mass balance for the snowpack is computed as follows:

$$
\text { SWE }=\text { SNOW }- \text { aSNOWMELT, }
$$

$$
\text { aSNOWMELT }=(0.1+\text { SNOWCOVER } \times 0.9)
$$$$
\times \text { PSNOWMELT, }
$$

where aSNOWMELT is the actual snowmelt ( $\mathrm{mm}$ of water), SNOWCOVER is the percentage of snow over the catchment, and PSNOWMELT is the potential snowmelt.

2) $\mathrm{DD} / \mathrm{EB}$ MODELS

(i) $S E B$

For the SEB model (Machguth et al. 2006), the energy and mass balances within the snowpack are given by

$$
\mathrm{SWE}=\mathrm{SNOW}-\mathrm{SNOWMELT},
$$

with

$$
\text { SNOWMELT }=\frac{\operatorname{ISR} \times(1-\alpha)+C_{0}+C_{1} \times T}{\rho \times L_{f}} \times 1000,
$$

where $\alpha$ is the snow albedo, ISR is the incoming shortwave radiation $\left(\mathrm{W} \mathrm{m}^{-2}\right), C_{0}$ and $C_{1}$ are factors accounting for the temperature-dependent energy fluxes $\left(\mathrm{W} \mathrm{m}^{-2}\right.$ and $\mathrm{W} \mathrm{m}{ }^{-2}{ }^{\circ} \mathrm{C}^{-1}$, respectively), $\rho$ is the density of snow $\left(\mathrm{kg} \mathrm{m}^{-3}\right)$, and $L_{f}$ is the fusion latent heat $\left(\mathrm{J} \mathrm{kg}^{-1}\right)$.

\section{(ii) ETI}

The ETI model (Pellicciotti et al. 2005) estimates the energy and mass balances in the snowpack following these two equations:

$$
\mathrm{SWE}=\mathrm{SNOW}-\mathrm{SNOWMELT},
$$

with

$$
\begin{aligned}
\mathrm{SNOWMELT}= & \mathrm{SR}_{f} \times(1-\alpha) \times \mathrm{ISR} \\
& +T_{f} \times T \text { if } T>T_{s},
\end{aligned}
$$

where $\mathrm{SR}_{f}$ and $T_{f}$ are the factors for the shortwave radiation $\left(\mathrm{m}^{2} \mathrm{~mm}^{-1} \mathrm{~W}^{-1} \mathrm{day}^{-1}\right)$ and temperature $\left(\mathrm{mm}^{\circ} \mathrm{C}^{-1} \mathrm{day}^{-1}\right)$, respectively.

\section{(iii) HYDROTEL}

In the HYDROTEL SM (Turcotte et al. 2007), a mass balance is used to calculate the SWE as

$$
\mathrm{SWE}=\mathrm{PLIQ}+\mathrm{SNOW}-M+\mathrm{WATER},
$$

with

$$
M=\frac{-U}{C_{f} \times \rho_{w}},
$$


where WATER is the snow water equivalent on the ground ( $\mathrm{mm}$ of water), PLIQ is liquid precipitation ( $\mathrm{mm}$ of water), $M$ is melting water ( $\mathrm{mm}$ of water), $U$ is the calorific deficit $\left(\mathrm{J} \mathrm{m}^{-2}\right), C_{f}$ is the melting heat $\left(\mathrm{J} \mathrm{kg}^{-1}\right)$, and $\rho_{w}$ is the water density $\left(\mathrm{kg} \mathrm{m}^{-3}\right)$.

\section{b. Description of potential evapotranspiration methods}

Five PET computation methods are evaluated in this study. These methods are classified into temperaturebased methods [Hamon (HAM) and MOHYSE (MOH)] and radiation-based methods [Oudin (OUD), PriestleyTaylor (PT), and Penman-Monteith (PM)]. Table 3 lists the conceptual differences between the five PET methods. In sections $3 b(1)$ and $3 b(2)$, the PET algorithms are briefly described.

\section{1) Temperature-BAsed methods}

(i) Hamon

The Hamon PET method (Hamon 1961) is computed as

$$
\mathrm{PET}=\frac{29.8 \times \mathrm{DL} \times \mathrm{SVD}}{\bar{T}+273.3},
$$

with

$$
\mathrm{SVD}=0.6108 \exp \left(\frac{\bar{T} \times 17.27}{\bar{T}+237.3}\right)
$$

where DL is the length of daytime corresponding to the sunrise to sunset in multiples of $12 \mathrm{~h}$ for a given latitude, $\bar{T}$ is the mean temperature of air $\left({ }^{\circ} \mathrm{C}\right)$, and SVD is the saturated vapor density $(\mathrm{hPa})$ for a given mean air temperature.

(ii) MOHYSE

The PET computation method derived from MOHYSE (Fortin and Turcotte 2007) is expressed by

$$
\mathrm{PET}=\frac{\mathrm{ESAT}}{0.6108 \times \pi} \times \cos ^{-1}\left[-\tan \left(\frac{L \times \pi}{180}\right) \times \tan (S)\right],
$$

with

$$
S=0.41 \times \sin \left(\frac{\text { day }-80}{365} \times 2 \pi\right),
$$

where $S$ is the daily solar declination.

\section{2) RADIATION-BASED METHODS}

\section{(i) Oudin}

The PET Oudin formula (Oudin et al. 2005) is based upon the daily extraterrestrial solar radiation $R_{e}$ as

$$
\begin{array}{ll}
\mathrm{PET}=\frac{R_{e} \times(T+5)}{\lambda \times \rho_{w} \times 100} & \text { if } T+5>0, \\
\mathrm{PET}=0 & \text { otherwise }
\end{array}
$$

where $T$ is the temperature of air $\left({ }^{\circ} \mathrm{C}\right), \lambda$ is the vaporization latent heat $\left(\mathrm{MJ} \mathrm{kg}^{-1}\right), R_{e}$ is the extraterrestrial radiation $\left(\mathrm{MJ} \mathrm{m}^{-2}\right)$, and $\rho_{w}$ is the water density $\left(\mathrm{kg} \mathrm{m}^{-3}\right)$.

\section{(ii) Penman-Monteith}

The Penman-Monteith formula (Monteith 1965) is given by

$$
\mathrm{PET}=\frac{s R_{n}+\rho_{a} \times c_{p}\left(e_{d}-e_{a}\right) / r_{a}}{\lambda \times \rho_{w} \times\left[s+\gamma\left(1+\frac{r_{s}}{r_{a}}\right)\right]},
$$

where $R_{n}$ is the net solar radiation $\left(\mathrm{MJ} \mathrm{m}^{-2} \mathrm{~d}^{-1}\right), s$ is the vapor pressure curve slope $\left(\mathrm{kPa}^{\circ} \mathrm{C}^{-1}\right), \rho_{a}$ is the density of air $\left(\mathrm{kg} \mathrm{m}^{-3}\right), e_{d}$ is the air saturation vapor pressure $(\mathrm{kPa}), e_{a}$ is the water vapor pressure of air $(\mathrm{kPa}), c_{p}$ is the specific heat at constant pressure $\left(\mathrm{MJ} \mathrm{kg}^{-1}{ }^{\circ} \mathrm{C}^{-1}\right), \gamma$ is the psychrometric constant $\left(\mathrm{kPa}^{\circ} \mathrm{C}^{-1}\right), r_{s}$ is the plant canopy resistance $\left(\mathrm{s} \mathrm{m}^{-1}\right)$, and $r_{a}$ is the aerodynamic resistance $\left(\mathrm{s} \mathrm{m}^{-1}\right)$.

(iii) Priestley-Taylor

The Priestley-Taylor's equation is expressed as

$$
\mathrm{PET}=\frac{\alpha_{a} \times \Delta R_{n}}{\lambda \times \rho_{w} \times(s+\gamma)} \quad \text { with } \quad \alpha_{a}=1.26 .
$$

\section{c. HM description}

\section{1) GR4J}

The modèle du Génie Rural à 4 paramètres Journalier (GR4J) rainfall-runoff model is a conceptual model with four parameters, operating at the daily time step (Perrin et al. 2003). It has been used in many research works (Velázquez et al. 2015b; Troin et al. 2015b). GR4J is composed of a production and a routing store. Required input data are potential evapotranspiration and precipitation.

\section{2) MOHYSE}

The conceptual and lumped MOHYSE model (Fortin and Turcotte 2007) was used in streamflow prediction at ungauged sites (Arsenault et al. 2015a) and in multimodel ensemble studies (Troin et al. 2015b). A production store and a routing store compose the model, with 10 parameters. Daily mean temperature and daily precipitation are necessary to run the model.

\section{3) HMETS}

The conceptual and lumped HMETS model uses two reservoirs for the saturated and vadose zones. The 
TABLE 3. Conceptual differences between model components for the PET computation methods. The acronyms of models and methods used in this study are also specified; $T=$ temperature, lat $=$ latitude, $R_{e}=$ extraterrestrial solar radiation, $p=$ surface pressure, $\mathrm{sH}=$ specific humidity, $w=$ wind speed, and $R_{n}=$ net radiation.

\begin{tabular}{llll}
\hline \hline \multicolumn{1}{c}{ PET methods } & \multicolumn{1}{c}{ Method type } & \multicolumn{1}{c}{ Input data $^{\mathrm{a}}$} & \multicolumn{1}{c}{ References } \\
\hline Hamon (HAM) & Temperature-based & $T$, lat & Hamon (1961) \\
MOHYSE (MOH) & Temperature-based & $T$, lat & Fortin and Turcotte (2007) \\
Oudin (OUD) & Radiation-based & $T, R_{e}$ & Oudin et al. (2005) \\
Penman-Monteith (PM) & Radiation-based & $T, p, \mathrm{sH}, w, R_{n}$ & Monteith (1965) \\
Priestley-Taylor (PT) & Radiation-based & $T, p, \mathrm{sH}, w, R_{n}$ & Priestley and Taylor (1972) \\
\hline
\end{tabular}

hydrological processes simulated by the model are infiltration, evapotranspiration, snow melting and accumulation, and flow routing toward the outlet of the catchment. HMETS with these 21 parameters requires daily maximum and minimum temperature and daily precipitation data. The model was used in multimodel projects (Arsenault et al. 2015b) as well as in impact studies of climate change (Chen et al. 2011a). Readers can refer to Troin et al. (2015b) for additional information about the three HMs.

\section{d. Model calibration, evaluation, and uncertainty}

The calibration of the 105 multimodel combinations is performed using all the CRCM ensemble simulations. For each SM-PET-HM combination, the parameters are calibrated based on the daily pseudo-observed discharge on even years, and the performance of the combination models is validated on odd years with the daily pseudoobservations for the 1961-90 period. An evaluation of the simulations is then made over a period of 20 years for current (1971-90) and future (2041-60) climates, where daily simulated streamflows $Q$ are compared to the pseudo-observations in the virtual world.

The uncertainties in the projections of future streamflow are evaluated by analyzing the impacts of the model components (SM versus PET versus HM structure) and the uncertainty of the natural climate variability (CRCM ensemble simulations). To that end, three flow indicators are chosen: mean annual flow (MF); spring high flow (HF), which is the maximum flow observed in one day (March-June); and summer low flow (LF), defined as the lowest 7-day average flow (July-October). For each flow indicator, the pseudo-observed and simulated climate change signals (CCS) are calculated as

$$
\begin{aligned}
\mathrm{CCS}_{\text {pseudo-obs }}(\%) & =\frac{\left(\mathrm{FI}_{\text {pseudo-obs }}^{\mathrm{fut}}-\mathrm{FI}_{\text {pseudo-obs }}^{\mathrm{ref}}\right)}{\mathrm{FI}_{\text {pseudo-obs }}^{\text {ref }}} \times 100 \\
\mathrm{CCS}_{\text {sim }}(\%) & =\frac{\left(\mathrm{FI}_{\text {sim }}^{\mathrm{fut}}-\mathrm{FI}_{\text {sim }}^{\mathrm{ref}}\right)}{\mathrm{FI}_{\text {sim }}^{\mathrm{ref}}} \times 100
\end{aligned}
$$

where $\mathrm{FI}_{\text {sim }}^{\mathrm{ref}}$ and $\mathrm{FI}_{\text {pseudo-obs }}^{\mathrm{ref}}$ are the simulated and pseudo-observed flow indicators (MF, HF, or LF) over the 20-yr reference period, respectively, and $\mathrm{FI}_{\text {sim }}^{\mathrm{fut}}$ and $\mathrm{FI}_{\text {pseudo-obs }}^{\text {fut }}$ are the simulated and pseudo-observed flow indicators (MF, HF, or LF) over the 20-yr future period, respectively.

The magnitudes of uncertainty sources in the climate change signals of the flow indicators in the virtual world are isolated and compared by using the variance decomposition method (Kendall et al. 1977; von Storch and Zwiers 1999). The present approach follows Roberts and Snelgrove (2015), Déqué et al. (2007), and Ferro (2004).

Let $I_{\text {sehc }}$ be the climate change signal on a given flow indicator for SM $s$ varying from 1 to 7, PET method $e$ varying from 1 to $5, \mathrm{HM} h$ varying from 1 to 3 , and natural climate variability $c$ varying from 1 to 2 (twomember ensemble of the CRCM). The total variance of $I_{\text {sehc }}$ is decomposed as

$$
\begin{aligned}
V\left(I_{\text {sehc }}\right)= & S+E+H+C+S E+S H+S C+E H+E C \\
& +H C+S E H+S E C+S H C+E H C+S E H C,
\end{aligned}
$$

with, for example,

$$
\begin{aligned}
& S=\frac{1}{7} \sum_{s=1}^{7}\left(\mathrm{FI}_{\text {seø॰ }}-\mathrm{FI}\right)^{2} \text { and }
\end{aligned}
$$

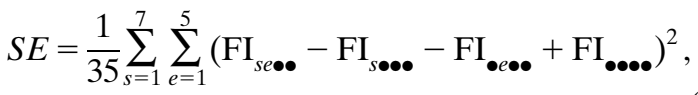

where $\bullet$ is the average of the index it has substituted. The terms of Eq. (23) are expressed in percentages of variance. The total variance attributed to the SM can be expressed, for example, as

$$
\begin{aligned}
V(S)= & S+S E+S H+S C+S E H+S E C \\
& +S H C+S E H C .
\end{aligned}
$$

The magnitudes of $V(S), V(E), V(H)$, and $V(C)$ indicate the effect of each uncertainty source on the value of the climate change signal for a given flow indicator. 


\section{Results}

\section{a. Evaluating the multimodel approach over current climate}

Before comparing the reliability of the multimodel combinations at reproducing pseudo-observed streamflows under the historical period, the performance of the HMs during calibration and validation periods is analyzed. For each HM, the 35-simulation Nash-Sutcliffe (NS) values (7 SMs $\times 5$ PET methods) are evaluated per catchment for the calibration and validation (Fig. 3). Model evaluations are performed on the daily hydrological data. Results show that the HMs differ in performance; the MOHYSE and HMETS ensembles of 35 simulations perform well, with NS scores from 0.61 to 0.91 for the calibration and from 0.53 to 0.88 for the validation over the two basins. The GR4J ensemble performance is lower, with NS scores between 0.24 and 0.82 (median of 0.52 ) over the validation period. We then compare the pseudo-observed discharges in the virtual world with the observed discharges from the cQ2 database for the 1961-90 period. The agreement between the pseudo-observed discharges and the observations is satisfactory, with NS values of 0.72 over the Mistassini basin and 0.82 over the Arnaud basin, giving credence to the virtual world approach for the present experiments.

Figures 4 and 5 present the 20 -yr pseudo-observed and simulated monthly mean discharges under current climate for the Mistassini basin and the Arnaud basin, respectively. The three HM ensemble simulations capture the timing of the spring peak flow over the two catchments. Overall, the MOHYSE and HMETS ensemble simulations provide a fairly good simulation of the magnitude of the spring peak flows over the basins; however, an underestimation of the magnitude of the spring peak flow is observed with the GR4J ensemble simulations over the two basins (mean relative bias of $16 \%)$. The performance is similar for the DD and $\mathrm{DD} / \mathrm{EB}$ SMs in the SM-PET-HM combinations over the two basins, indicating a lack of sensitivity of the HMs to the SMs under the current climate. The PET methods have the strongest effect on the discharge simulations compared with the SMs for the catchments under investigation. Significant variations in the magnitude of the HM-simulated seasonal streamflows are obtained according to the PET methods, particularly when the PET methods are combined with HMETS and GR4J. The two approaches of the PET methods in the SMPET-HM combinations result in contrasted seasonal streamflow simulations. For instance, the summer flows (JJA) are clearly overestimated in the GR4J ensemble simulations over the Mistassini basin, when the two temperature-based PET methods (HAM and $\mathrm{MOH})$ are combined with the SMs. This is confirmed with the analysis of percent deviation values in Supplemental Material 1 (available online). From Figs. 4 and 5, we can see that the HM structure has an impact on the streamflow simulations, with noticeable variations throughout the year. However, all the HM structures lead to underestimated mean annual streamflows over the basins. We can note that distributions of the percent deviation values differ between the CRCM simulations under the current climate for the study basins.

\section{b. Evaluating the multimodel approach over future climate}

The performance of the multimodels is then evaluated under the future climate by comparing the simulated streamflows from the SM-PET-HM combinations with the pseudo-observations.

Figures 6 and 7 show the 20-yr pseudo-observed and simulated monthly mean discharges for the Mistassini basin and the Arnaud basin, respectively, over the future period. The timing of the spring peak flow is fairly well represented in the simulations over the two basins, but none of the HM ensemble simulations capture its magnitude. Again, this provides indications that the SMs cannot accurately represent the magnitude of the snowmelt peak under the future climate over the study basins. The GR4J ensemble simulations still give the worst representations of the magnitude of peak flows over both basins. As expected, the DD and DD/EB SM in the SM-PET-HM combinations exhibit similar performances at simulating streamflows under the future climate, with equal mean percent deviation values. The discrepancies between the simulated and pseudoobserved seasonal discharges also give a hint of the effect of the selected PET method in the HM; the seasonal cycle of streamflows under the future climate strongly differs according to the PET methods through the SM-PET-HM combinations (Figs. 6, 7). From an analysis of percent deviation values in Supplemental Material 2, we can see that the lowest performances of the ensemble simulations are based on the temperature-based PET methods. In contrast, when PET is computed with radiation-based equations, the performance of the SM-PET-HM combinations is more acceptable. The comparison of future pseudo-observed and simulated seasonal streamflows confirms the influence of the HM structure on the reliability of streamflow simulations, as previously detected under the current climate (Figs. 4, 5). Results are relatively homogenous between MOHYSE and HMETS, but GR4J systematically provides contrasted seasonal streamflow simulations, independently 
(A) Calibration
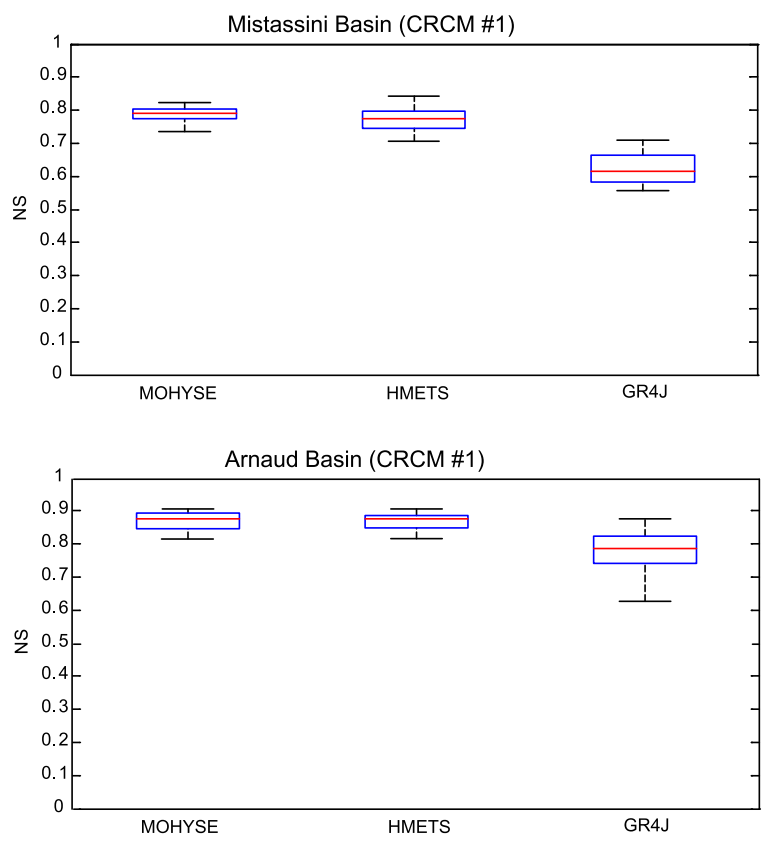

(B) Validation
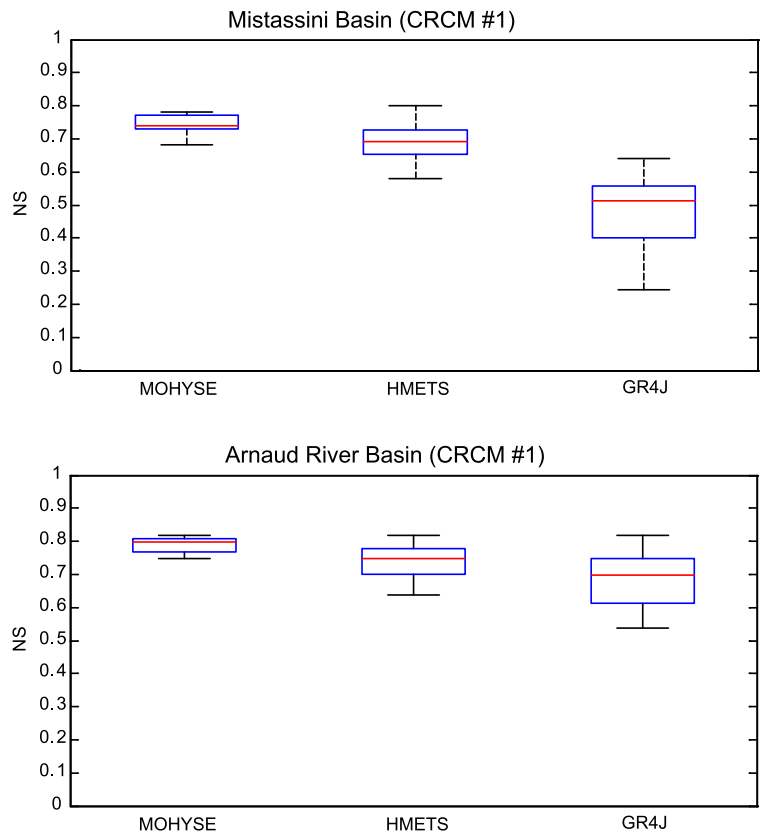
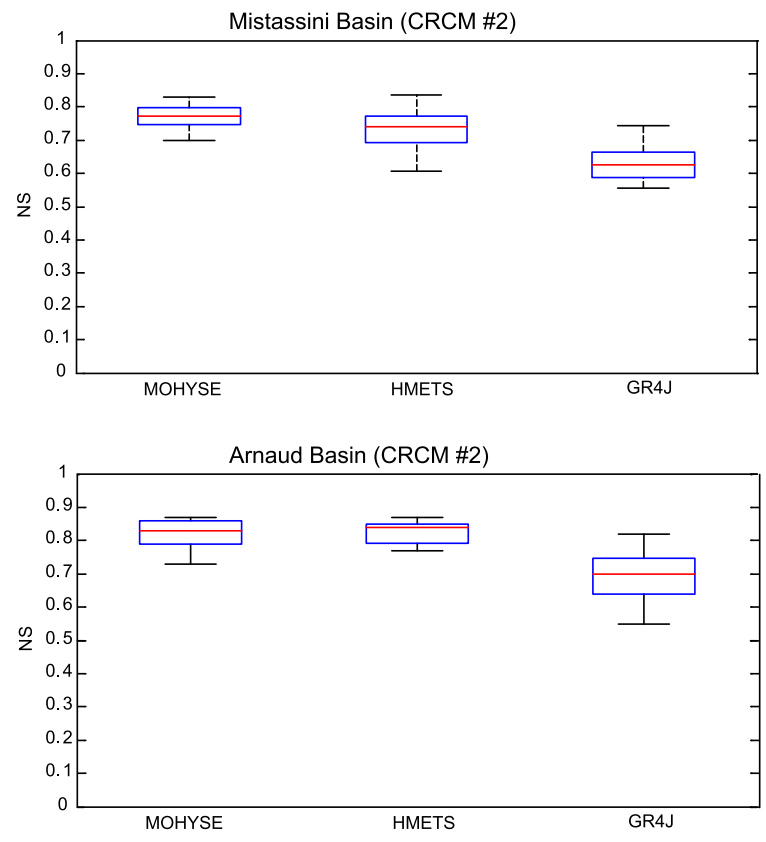

FIG. 3. Performance of the multimodels to simulate streamflow over the 15-yr (a) calibration and (b) validation period over the study basins. The performance is expressed in terms of NS efficiency criterion based on the 35 SM-PET combinations per HM (MOHYSE, HMETS, and GR4J). For instance, in (a), for the Mistassini basin (CRCM 1), the MOHYSE box represents the 35 NS values for all the SM-PET-MOHYSE combinations. The whiskers represent the higher and lower NS values among the 35 SM-PET-MOHYSE combinations, whereas the box presents the 25 th, 50th, and 75 th quantiles. The left column represents the results obtained with CRCM 1 , and the right column represents those obtained with CRCM 2. Each line represents the results to a considered catchment. 

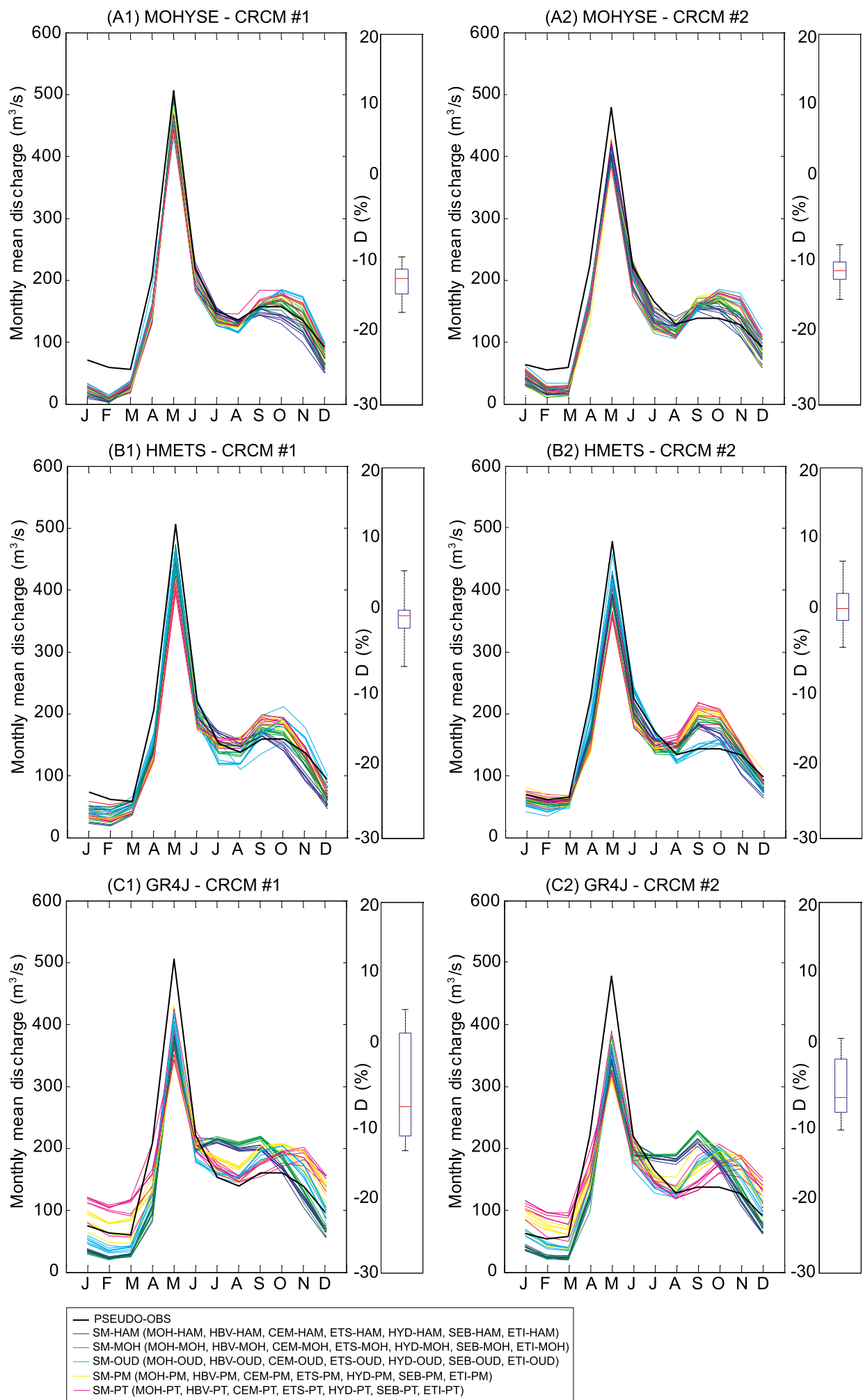

FIG. 4. Mean monthly discharges simulated using the CRCM ensemble simulations as input to the multimodels over the Mistassini basin for the 1971-90 period. The simulations are compared to the pseudoobserved discharges (PSEUDO-OBS) from the virtual world under the current climate. The box plots to the right present the percent deviation $D$ of streamflow (\%). For instance, in the box plot in the top-left panel, the box represents the $35 \mathrm{D}$ values for all the SM-PET-MOHYSE combinations obtained with CRCM 1. The whiskers represent the higher and lower $D$ values among the 35 SM-PET-MOHYSE combinations, whereas the box presents the 25 th, 50th, and 75th quantiles. Same description for the other two models, HMETS and GR4J, with the two CRCM ensemble simulations (CRCM 1 and CRCM 2). 

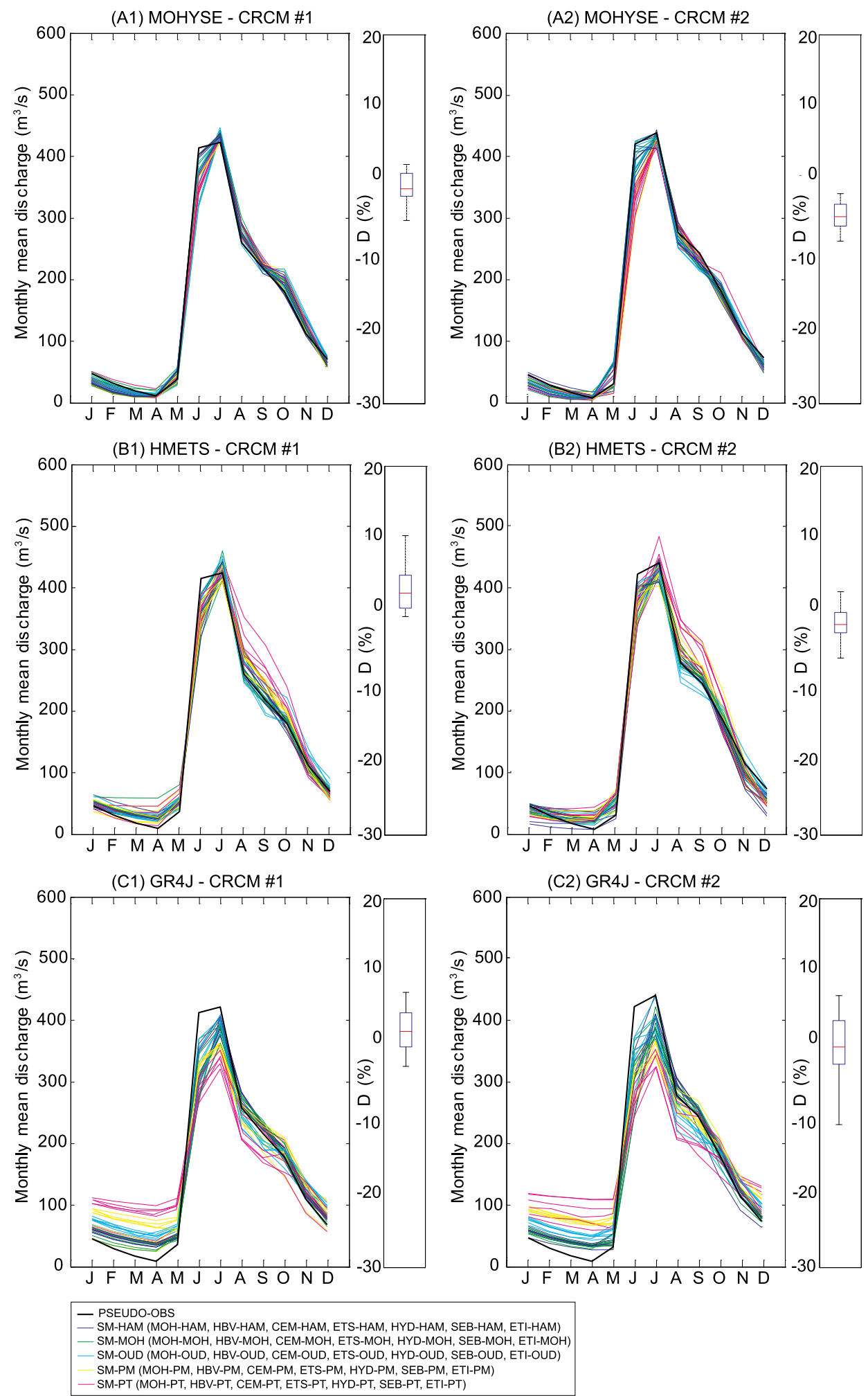

FIG. 5. As in Fig. 4, but for the Arnaud basin. 

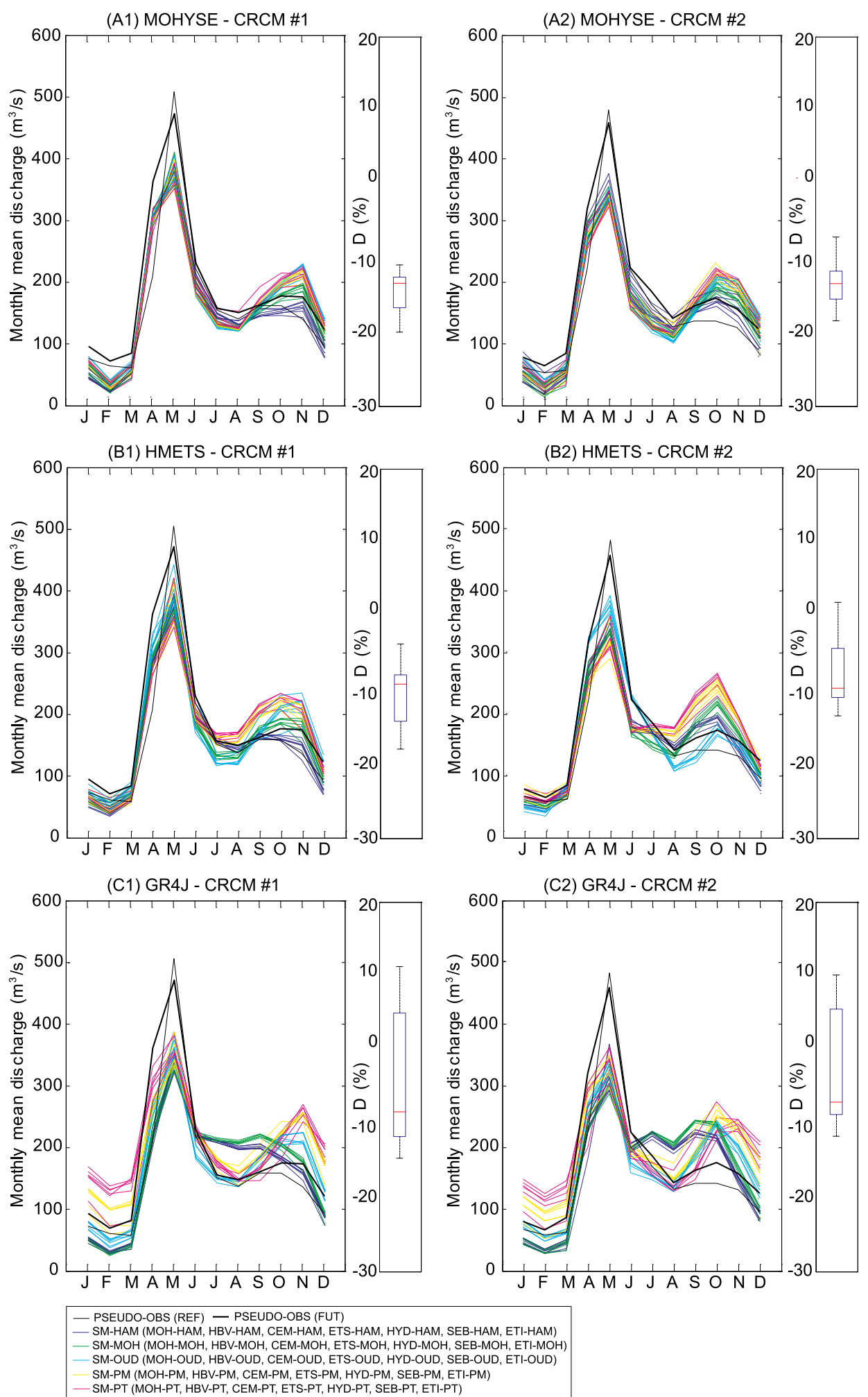

FIG. 6. As in Fig. 4, but for mean monthly discharges simulated using the CRCM ensemble simulations as input to the multimodels over the Mistassini basin for the 2041-60 period. The simulations are compared to the pseudo-observed discharges (PSEUDO-OBS) from the virtual world under the future climate. The pseudo-observed simulations in the virtual world under the current climate are also plotted for comparison. 

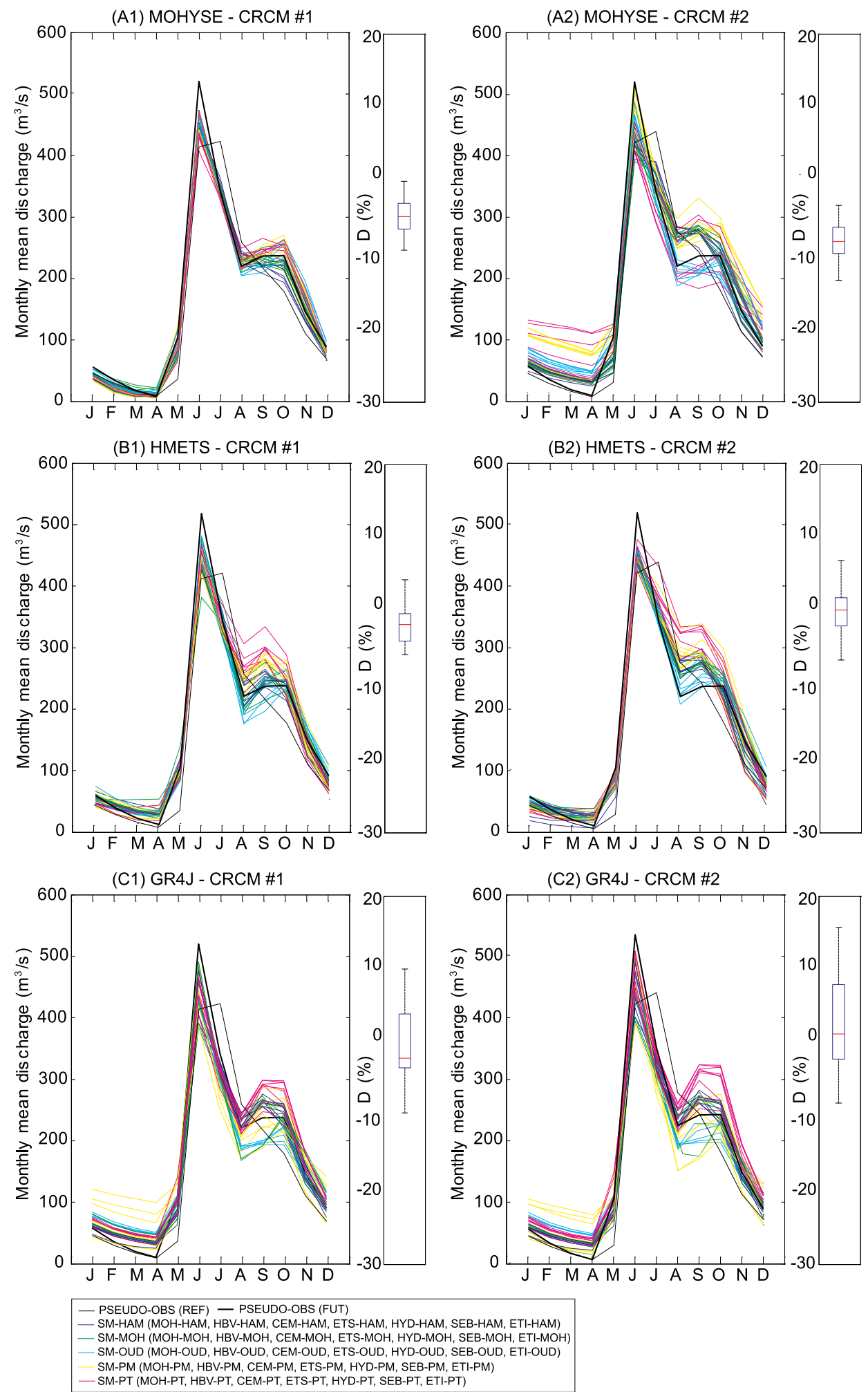

FIG. 7. As in Fig. 6, but for the Arnaud basin. 
of the SM-PET combination. The spread of the ensemble simulations is larger for the GR4J ensemble than for the two other HMs' ensembles under the future climate (Figs. 6, 7), and also under the current climate (Figs. 4, 5). However, all the HM ensemble simulations lead to underestimated mean annual streamflows for the future period. Similar to the historical period, the spread of the streamflow simulations is large according to the two CRCM simulations used to drive the SM-PET-HM combinations for the future period (Figs. 6, 7).

\section{c. Impacts of climate change on the virtual hydrological cycle}

The climate change impacts on future hydroclimate conditions are analyzed over the two study basins. From Table 4, we can see that important changes are probable to occur for temperature and precipitation at the 2050 horizon, with a mean annual change of $3.2^{\circ}-3.4^{\circ} \mathrm{C}$ for temperature and $22 \%-47 \%$ for precipitation over the basins. All of the HM simulations show an increase in MFs over the basins from $15 \%$ to $25 \%$, although this trend seems to be more noticeable for the northernmost basin (Fig. 1).

For the Mistassini basin, the projections of the timing of the spring peak flow at the 2050 horizon coincide with the present-day peak flow (Figs. 4, 6); its magnitude is likely to decrease by $11 \%-19 \%$ over the Mistassini basin according to the HM ensemble simulations. However, for the Arnaud basin, an earlier spring peak flow is observed at the 2050 horizon, with an advance of one month and an increased magnitude of $9 \%-58 \%$ (Figs. 5, 7). The JJA and autumn (SON) streamflows are projected to increase by $0 \%-6 \%$ and by $15 \%-17 \%$, respectively, according to the $\mathrm{HM}$ ensemble simulations over the Mistassini basin. A high increase in winter streamflows (DJF) of $37 \%-60 \%$ is also expected over this basin. The Arnaud basin exhibits more pronounced changes in seasonal streamflows, with increased winter and autumn flows by $19 \%-69 \%$ and by $10 \%-65 \%$, respectively, according to the HM ensemble simulations. The summer streamflows are expected to vary between $-12 \%$ and $59 \%$ according to the HM ensemble simulations over the basin. In addition, the figures show large differences in the seasonal streamflow projections between the two CRCM simulations within each HM ensemble simulation over the two basins. This indicates a high sensitivity of the SMPET-HM combinations to the climate model simulations. A detailed analysis of changes in mean annual flows as simulated by each SM-PET-HM combination using the CRCM ensemble simulations following the A2 scenario for the two basins can be found in Supplemental Material 3.
TABLE 4. Changes in annual precipitation (\%) and mean temperature $\left({ }^{\circ} \mathrm{C}\right)$ as projected by the CRCM ensemble for the A2 scenario and in MF (\%) as simulated by the multimodels over the study basins for the 2041-60 period relative to the 1971-90 period. The range of changes for the ensemble simulations is displayed in parentheses. The values in brackets correspond to the pseudoobserved changes of annual mean flows.

\begin{tabular}{lcc}
\hline \hline & Mistassini basin & Arnaud basin \\
\hline$P$ & $22(20-24)$ & $44(39-48)$ \\
$T$ & $3.2(3.0-3.3)$ & $3.4(3.2-3.6)$ \\
MF & $15(9-23)[15(13-16)]$ & $23(8-44)[27(25-29)]$ \\
\hline
\end{tabular}

\section{Uncertainty analyses and discussion}

\section{a. Uncertainty in streamflow projections}

This section evaluates the uncertainties in streamflow projections by analyzing the impacts of the model components (SM, PET, and HM structure) and of natural climate variability (CRCM two-member ensemble). The main interest is to estimate the role of the four sources of uncertainty on the projected streamflows. To that end, variance decomposition is performed on the signal of climate change for the three selected hydrologic indicators (MF, HF, LF; see section 3d). The changes in the flow indicators at the 2050 horizon are given in Table 5.

The 15 percentages of variance explained for the three flow indicators over the two basins are presented in Table 6. Of the four primary terms, the HM structure $H$ has the highest values for the three indicators over the Arnaud basin. The findings are somewhat contrasted for the Mistassini basin, where the term of PET methods $E$ dominates for MF variance and that of natural climate variability $C$ dominates for $\mathrm{HF}$ and $\mathrm{LF}$ variances. The snow models $S$ term does not contribute much to MF variance; however, the influence of the snow model is slightly amplified for HF and LF variances over the two basins. The $E H$ term, which is the interaction between the choice of the PET methods and the choice of the HM structure, is the dominant second interaction term for the three indicators across the basins. The third and fourth interaction terms (from $S E H$ to $S E H C$ in Table 6) are below $10 \%$.

The 15 terms are then aggregated to give $V(S), V(E)$, $V(H)$, and $V(C)$. For example, the total variance attributed to the snow models is given by $V(S)=S+S E+$ $S H+S C+S H E+S E C+S E H C$. In this case, the total variances are not equal to $100 \%$ because of the interaction terms. From the analysis of Table 7, we can see that the results are not spatially homogenous between the study catchments. For the Mistassini basin, the uncertainty due to the PET methods is the largest out of the four for the MF projections, whereas the main 
TABLE 5. As in Table 4, but for changes in MF, HF and LF (\%). The values in brackets correspond to the pseudo-observed changes of the flow indicators.

\begin{tabular}{ccc}
\hline \hline Flow indicators & Mistassini basin & Arnaud basin \\
\hline MF & $12(7$ to 22$)[1(-11$ to 23$)]$ & 21 (7 to 38$)[21(-8$ to 49$)]$ \\
HF & $2(-13$ to 34$)[0(-28$ to 74$)]$ & $15(-7$ to 68$)[24(-25$ to 117$)]$ \\
LF & $-5(-38$ to 16$)[-17(-58$ to 32$)]$ & $27(-11$ to 60$)[25(-66$ to 82$)]$ \\
\hline
\end{tabular}

uncertainty for the HF and LF projections is the natural climate variability. The choice of the HM structure has an impact on the MF and HF projections over this basin, but with a slightly lower intensity. For the northernmost basin, the HM structure clearly dominates for the MF and HF projections. These findings can be partially extended to LF, where uncertainty due to the PET methods is also significant. Uncertainty associated with the natural climate variability is therefore marginal for these basins.

An explanation for these findings might be that the PET methods do not have a strong effect on streamflow projections for the northern basin compared to the southern basin because of low precipitation and temperature (Table 1). Given the low temperature and precipitation values for the northern basin, the variability of temperature and precipitation between the CRCM members can only be small and, by extension, the uncertainty related to the natural climate variability in streamflow projections is insignificant. On the contrary, the natural climate variability should influence streamflow projections for the southern basin because of the higher climate variability. This should also imply that the signal of climate change on streamflows should be stronger over the northern basin in comparison to the southern basin (Tables 4 and 5 ). Note that the present experiments are based upon two members of the CRCM, limiting the evaluation of natural climate variability. As expected, the snow models do not contribute to uncertainty in the projections of the three hydrologic indicators over the study basins (Troin et al. 2016).

\section{b. Implications for hydrological impact studies}

Evaluating the effects of climate change on streamflows is challenging, as the various modeling stages are associated with uncertainties. Of the five uncertainties that need to be explored in impact studies, the uncertainty associated with hydrological modeling must be considered, since large differences in streamflow change projections are observed between models (Bae et al. 2011; Velázquez et al. 2015a). The uncertainty of model structure is not well understood to date, and additional works are necessary to evaluate the level of uncertainty attributed to each model component. Such an evaluation will contribute to reduce the hydrological modeling uncertainty in impact studies.

The design of the present experiment, conducted in the virtual world, allowed the testing of a larger ensemble of SM-PET-HM combinations. The results indicate that the dominant source of uncertainty for future streamflow simulations is not attributed to the selected SMs for the basins under investigation. Both the DD and DD/EB SMs through the SM-PET-HM combinations lead to similar streamflow simulations at the 2050 horizon. Our findings are in agreement with the previous works of Troin et al. (2015b, 2016). The influence of PET methods on streamflow projections is also explored. The various PET methods provide a large spread of streamflow changes that varies over the study basins. The differences in streamflow change are apparent between the temperature-based and radiation-based PET methods through the SM-PET-HM combinations. Higher streamflow changes are expected with the radiation-based PET methods. Note that the radiation-

TABLE 6. Percentage of variance explained by the 15 terms in the decomposition of the climate change signals on MF, HF and LF over the Mistassini and Arnaud basins for the 2041-60 period relative to the 1971-90 period.

\begin{tabular}{|c|c|c|c|c|c|c|c|c|c|c|c|c|c|c|c|}
\hline Flow indicators & $S$ & $E$ & $H$ & $C$ & $S E$ & $S H$ & $S C$ & $E H$ & $E C$ & $H C$ & $S E H$ & $S E C$ & $S H C$ & EHC & $S E H C$ \\
\hline & \multicolumn{15}{|c|}{ Mistassini basin } \\
\hline MF & 1 & 43 & 22 & 1 & 1 & 3 & 1 & 10 & 1 & 9 & 3 & 1 & 1 & 1 & 2 \\
\hline $\mathrm{HF}$ & 4 & 7 & 18 & 38 & 1 & 1 & 1 & 14 & 0 & 1 & 4 & 3 & 2 & 1 & 5 \\
\hline $\mathrm{LF}$ & 1 & 9 & 7 & 56 & 1 & 1 & 1 & 11 & 2 & 3 & 2 & 1 & 1 & 3 & 2 \\
\hline \multicolumn{16}{|c|}{ Arnaud basin } \\
\hline MF & 4 & 15 & 26 & 0 & 3 & 4 & 0 & 18 & 1 & 8 & 9 & 2 & 3 & 2 & 5 \\
\hline $\mathrm{HF}$ & 5 & 3 & 50 & 0 & 4 & 3 & 5 & 7 & 3 & 1 & 6 & 2 & 2 & 5 & 4 \\
\hline $\mathrm{LF}$ & 10 & 22 & 21 & 3 & 4 & 4 & 1 & 9 & 0 & 7 & 9 & 2 & 2 & 1 & 5 \\
\hline
\end{tabular}


TABLE 7. Percentage of the total variance explained by the snow models $V(S)$, the PET methods $V(E)$, the hydrological models $V(H)$, and the natural climate variability $V(C)$ in the decomposition of the climate change signals on MF, HF and LF over the Mistassini and Arnaud basins for the 2041-60 period relative to the 1971-90 period.

\begin{tabular}{crrrr}
\hline \hline Flow indicators & $V(S)$ & \multicolumn{4}{c}{$V(E)$} & $V(H)$ & $V(C)$ \\
\hline & & \multicolumn{4}{c}{ Mistassini basin } \\
MF & 13 & 61 & 51 & 19 \\
HF & 20 & 36 & 45 & 51 \\
LF & 9 & 31 & 30 & 68 \\
& & \multicolumn{4}{c}{ Arnaud basin } \\
MF & 29 & 55 & 74 & 20 \\
HF & 30 & 34 & 78 & 22 \\
LF & 36 & 51 & 58 & 22 \\
\hline
\end{tabular}

based PET methods are also affected by temperature (Tables 2 and 3). Consequently, the discrepancies on streamflow change following the PET methods are linked to the sensitivity of the PET methods to both solar radiation and temperature changes. This implies that an HM can give a different representation to climate simulations following the selected PET method (temperaure-based versus radiation-based PET approach). The findings complement those of Bae et al. (2011), where the authors show that the changes on projected streamflows in the Chungju Dam basin (South Korea) are a function of the choice of the PET methods. Three different HM structures are also used in this work. We show that the selection of the HM structure directly affects streamflow projections. However, only three lumped conceptual hydrological models are selected for the purpose of this study. If additional different models had been applied in terms of structural variations (e.g., semidistributed and/or distributed models), then a better quantification of the role of the HM structure on the projected streamflows might have been achieved.

Considering the medium size of the simulations over two catchments, this work allows the role of the uncertainty sources on projected streamflows to be explored. The analysis of the variance decomposition demonstrated that the uncertainty associated with the choice of the HM structure dominates, followed by the uncertainty due to the choice of the PET methods or that of natural climate variability, depending on the hydrologic indicator and the study catchment. The choice of the HM structure causing more uncertainty than other model components shows the necessity of several numbers of model structures to include the uncertainty of the HM structure. In future studies, investigating the contribution of vertical and horizontal water flows in model structure would further enhance our understanding of structural uncertainty. The other
HM component that is affected by a variation in climate conditions is permafrost dynamics. An additional work will be done to explore the sensitivity of permafrost dynamics models to that of the SMs and PET methods on streamflow projections over Nordic catchments. Results also show that natural variability of climate has a nonnegligible effect on the uncertainty of projected streamflows over the study basins, which is coherent with other multimodel impact works (Booij 2005; Kay et al. 2009; Seiller and Anctil 2014; Troin et al. 2015a). However, the results obtained from this work are limited because of the implementation of the multimodels over just two catchments. More basins are required before the findings of the uncertainty analysis can be generalized to other regions.

\section{Summary and conclusions}

The present study compares multicombinations of SMs, PET methods, and HM structures at simulating pseudo-observed streamflows under the current climate and explores how these combinations of multimodels have an effect on the evaluation of climate change impacts at the basin scale. Here, seven SMs are combined with five PET methods through three HM structures to simulate pseudo-observed streamflows over two Quebec basins. The investigation is conducted in the virtual world based upon meteorological and hydrological data from the CRCM simulations. The relevant findings of this work are synthesized below.

1) Over the historical period (1961-90), the $105 \mathrm{SM}-$ PET-HM combinations per catchment provide satisfactory performances in simulating streamflows for calibration and validation. The spring peak flow's timing is generally properly captured by all the ensemble simulations over the two catchments. However, the magnitude of the spring peak flows is more or less adequately simulated according to the HM ensemble simulation over the study basins.

2) Over the future period (2041-60), the 105 SM-PETHM combinations per catchment have acceptable performances at simulating streamflows, comparable to those obtained for the historical period. While all the ensemble simulations provide satisfactory simulations of the spring peak flow's timing, again, none capture its magnitude.

3) The projections of future climate show that important changes in virtual streamflows are likely to happen in this century. For the Mistassini basin, the timing of the future spring peak flow is supposed to coincide with that of the present day, but with a decreased magnitude. However, over the Arnaud 
basin, an earlier spring peak flow is expected than for the historical period, with an increased magnitude.

4) A ranking of the uncertainty sources related to model components and natural climate variability in streamflow projections is provided. Of the analysis of specific hydrologic indicators using the decomposition of variance, it is shown that the selection of the HM structure contributes the most to uncertainty on the projected streamflows, followed by the choice of the PET methods or the natural climate variability, depending on the hydrologic indicator and the catchment. The SMs lead to the lowest level of uncertainty to the total uncertainty linked to model components.

This work gives pathways to assess the uncertainty of HM structure in impact studies. Exploring the HM structure uncertainty in greater detail by analyzing the uncertainty associated with both the horizontal and vertical water flow schemes will help to increase the understanding of model structure and, by extension, to reduce uncertainty on streamflow projections.

Acknowledgments. This study was funded by École de technologie supérieure (ETS). Ouranos supplied the CRCM simulations for this work. The authors also thank Hydro-Québec and IRSTEA for providing some snow models used in this study.

\section{REFERENCES}

Ajami, N. K., Q. Duan, Q. X. Gao, and S. Sorooshian, 2006: Multimodel combination techniques for analysis of hydrological simulations: Application to distributed model intercomparison project results. J. Hydrometeor., 7, 755-768, https:// doi.org/10.1175/JHM519.1.

Arsenault, R., and F. Brissette, 2014: Determining the optimal spatial distribution of weather station networks for hydrological modeling purposes using RCM datasets: An experimental approach. J. Hydrometeor., 15, 517-526, https:// doi.org/10.1175/JHM-D-13-088.1.

, and _ 2016: Analysis of continuous streamflow regionalization methods within a virtual setting. Hydrol. Sci. J., 61, 2680-2693, https://doi.org/10.1080/02626667.2016.1154557.

- D. Poissant, and F. Brissette, 2015a: Parameter dimensionality reduction of a conceptual model for streamflow prediction in Canadian, snowmelt dominated ungauged basins. Adv. Water Resour., 85, 27-44, https://doi.org/10.1016/ j.advwatres.2015.08.014.

_- P. Gatien, B. Renaud, F. Brissette, and J. L. Martel, 2015b: A comparative analysis of 9 multi-model averaging approaches in hydrological continuous streamflow prediction. J. Hydrol., 529, 754-767, https://doi.org/10.1016/ j.jhydrol.2015.09.001.

Bae, D. H., I. W. Jung, and D. P. Lettenmaier, 2011: Hydrologic uncertainties in climate change from IPCC AR4 GCM simulations of the Chungju Basin, Korea. J. Hydrol., 401, 90-105, https://doi.org/10.1016/j.jhydrol.2011.02.012.
Beauchamp, J., R. Leconte, M. Trudel, and F. Brissette, 2013: Estimation of the summer-fall PMP and PMF of a northern watershed under a changed climate. Water Resour. Res., 49, 3852-3862, https://doi.org/10.1002/wrcr.20336.

Bergström, S., 1976: Development and application of a conceptual runoff model for Scandinavian catchments. Swedish Meteorological and Hydrological Institute Rep. RH07, 134 pp.

Bohn, T. J., M. Y. Sonessa, and D. P. Lettenmaier, 2010: Seasonal hydrologic forecasting: Do multimodel ensemble averages always yield improvements in forecast skill? J. Hydrometeor., 11, 1358-1372, https://doi.org/10.1175/2010JHM1267.1.

Booij, M. J., 2005: Impact of climate change on river flooding assessed with different spatial model resolutions. J. Hydrol., 303, 176-198, https://doi.org/10.1016/j.jhydrol.2004.07.013.

Brigode, P., L. Oudin, and C. Perrin, 2013: Hydrological model parameter instability: A source of additional uncertainty in estimating the hydrological impacts of climate change? J. Hydrol., 476, 410-425, https://doi.org/10.1016/j.jhydrol.2012.11.012.

Caya, D., and R. Laprise, 1999: A semi-implicit semi-Lagrangian regional climate model: The Canadian RCM. Mon. Wea. Rev., 127, 341-362, https://doi.org/10.1175/1520-0493(1999)127<0341: ASISLR $>2.0 . \mathrm{CO} ; 2$.

Chen, J., F. Brissette, and R. Leconte, 2011a: Uncertainty of downscaling method in quantifying the impact of climate change on hydrology. J. Hydrol., 401, 190-202, https://doi.org/ 10.1016/j.jhydrol.2011.02.020.

$\longrightarrow,-$, A. Poulin, and R. Leconte, 2011b: Overall uncertainty study of the hydrological impacts of climate change for a Canadian watershed. Water Resour. Res., 47, W12509, https:// doi.org/10.1029/2011WR010602.

Clark, M. P., and Coauthors, 2016: Characterizing uncertainty of the hydrologic impacts of climate change. Curr. Climate Change Rep., 2, 55-64, https://doi.org/10.1007/s40641-016-0034-x.

de Elía, R., S. Biner, and A. Frigon, 2013: Interannual variability and expected regional climate change over North America. Climate Dyn., 41, 1245-1267, https://doi.org/10.1007/ s00382-013-1717-9.

Déqué, M., and Coauthors, 2007: An intercomparison of regional climate simulations for Europe: Assessing uncertainties in model projections. Climatic Change, 81, 53-70, https://doi.org/ 10.1007/s10584-006-9228-x.

Deser, C., R. Knutti, S. Solomon, and A. S. Phillips, 2012a: Communication of the role of natural variability in future North American climate. Nat. Climate Change, 2, 775-779, https:// doi.org/10.1038/nclimate1562.

— A. Phillips, V. Bourdette, and H. Teng, 2012b: Uncertainty in climate change projections: The role of internal variability. Climate Dyn., 38, 527-546, https://doi.org/10.1007/s00382-010-0977-x.

Duan, Q., N. K. Ajami, X. Gao, and S. Sorooshian, 2007: Multimodel ensemble hydrologic prediction using Bayesian model averaging. Adv. Water Resour., 30, 1371-1386, https://doi.org/ 10.1016/j.advwatres.2006.11.014.

Fatichi, S., S. Rimkus, P. Burlando, and R. Bordoy, 2014: Does internal climate variability overwhelm climate change signals in streamflow? The upper Po and Rhone basin case studies. Sci. Total Environ., 493, 1171-1182, https://doi.org/ 10.1016/j.scitotenv.2013.12.014

Ferro, C. A., 2004: Attributing variation in a regional climate change modelling experiment. PRUDENCE Working Note, 21 pp., http:// prudence.dmi.dk/public/publications/analysis_of_variance.pdf.

Flato, G. M., and G. J. Boer, 2001: Warming asymmetry in climate change simulations. Geophys. Res. Lett., 28, 195-198, https:// doi.org/10.1029/2000GL012121. 
Fortin, V., and R. Turcotte, 2007: Le modèle hydrologique MOHYSE (in French). Université du Québec à Montréal Note SCA7420, 14 pp., https://ena.etsmtl.ca/pluginfile.php/ 37357/mod_resource/content/1/MOHYSE_AP_oct2013.pdf

Fowler, H. J., S. Blenkinsop, and C. Tebaldi, 2007: Linking climate change modelling to impacts studies: Recent advances in downscaling techniques for hydrological modelling. Int. J. Climatol., 27, 1547-1578, https://doi.org/10.1002/joc.1556.

$\mathrm{Fu}, \mathrm{C}$., A. L. James, and H. Yao, 2015: Investigations of uncertainty in SWAT hydrologic simulations: A case study of a Canadian Shield catchment. Hydrol. Processes, 29, 4000-4017, https:// doi.org/10.1002/hyp.10477.

Georgakakos, K. P., D. J. Seo, H. V. Gupta, J. Schaake, and M. B. Butts, 2004: Towards the characterization of streamflow simulation uncertainty through multimodel ensembles. J. Hydrol., 298, 222-241, https://doi.org/10.1016/ j.jhydrol.2004.03.037.

Giorgi, F., and L. O. Mearns, 2002: Calculation of average, uncertainty range, and reliability of regional climate changes from AOGCM simulations via the "reliability ensemble averaging" (REA) method. J. Climate, 15, 1141-1158, https://doi.org/10.1175/ 1520-0442(2002)015<1141:COAURA $>2.0 . \mathrm{CO} ; 2$.

Hamon, W. R., 1961: Estimating potential evaporation. J. Hydraul. Div., Amer. Soc. Civ. Eng., 87, 107-120.

Haque, M. M., A. Rahman, D. Hagare, G. Kibria, and F. Karim, 2015: Estimation of catchment yield and associated uncertainties due to climate change in a mountainous catchment in Australia. Hydrol. Processes, 29, 4339-4349, https://doi.org/ 10.1002/hyp.10492.

Hawkins, E., and R. Sutton, 2009: The potential to narrow uncertainty in regional climate predictions. Bull. Amer. Meteor. Soc., 90, 1095-1107, https://doi.org/10.1175/2009BAMS2607.1. - and - 2011: The potential to narrow uncertainty in projections of regional precipitation change. Climate Dyn., 37, 407-418, https://doi.org/10.1007/s00382-010-0810-6.

Jung, I.-W., and H. Chang, 2011: Assessment of future runoff trends under multiple climate change scenarios in the Willamette River basin, Oregon, USA. Hydrol. Processes, 25, 258-277, https://doi.org/10.1002/hyp.7842.

Kay, A. L., H. N. Davies, V. A. Bell, and R. G. Jones, 2009: Comparison of uncertainty sources for climate change impacts: Flood frequency in England. Climatic Change, 92, 41-63, https://doi.org/10.1007/s10584-008-9471-4.

Kendall, M., A. Stuart, and J. K. Ord, 1977: Design and Analysis, and Time-Series. Vol. 3, The Advanced Theory of Statistics, 4th ed., Charles Griffin and Co. Ltd., 780 pp.

Langlois, A., A. Royer, E. Fillol, A. Frigon, and R. Laprise, 2004: Evaluation of the snow cover variation in the Canadian Regional Climate Model over eastern Canada using passive microwave satellite data. Hydrol. Processes, 18, 1127-1138, https://doi.org/10.1002/hyp.5514.

_ J. Bergeron, R. Brown, A. Royer, R. Harvey, A. Roy, L. Wang, and N. Thériault, 2014: Evaluation of CLASS 2.7 and 3.5 simulations of snow properties from the Canadian Regional Climate Model (CRCM4) over Québec, Canada. J. Hydrometeor., 15, 1325-1343, https://doi.org/10.1175/JHM-D-13-055.1.

Laprise, R., D. Caya, A. Frigon, and D. Paquin, 2003: Current and perturbed climate as simulated by the second-generation $\mathrm{Ca}$ nadian Regional Climate Model (CRCM-II) over northwestern North America. Climate Dyn., 21, 405-421, https://doi.org/ 10.1007/s00382-003-0342-4

Lindenschmidt, K. E., K. Fleischbein, and M. Baborowski, 2007: Structural uncertainty in a river water quality modelling system. Ecol. Modell., 204, 289-300, https://doi.org/10.1016/ j.ecolmodel.2007.01.004.

Liu, Y., and H. V. Gupta, 2007: Uncertainty in hydrologic modeling: Toward an integrated data assimilation framework. Water Resour. Res., 43, W07401, https://doi.org/10.1029/ 2006WR005756.

Lucas-Picher, P., P. Riboust, S. Somot, and R. Laprise, 2015: Reconstruction of the spring 2011 Richelieu River flood by two regional climate models and a hydrological model. J. Hydrometeor., 16, 36-54, https://doi.org/10.1175/JHM-D14-0116.1.

Lutz, A. F., W. W. Immerzeel, A. Gobiet, F. Pellicciotti, and M. F. P. Bierkens, 2013: Comparison of climate change signals in CMIP3 and CMIP5 multi-model ensembles and implications for central Asian glaciers. Hydrol. Earth Syst. Sci., 17, 3661-3677, https://doi.org/10.5194/hess-17-3661-2013.

Machguth, H., F. Paul, M. Hoelzle, and W. Haeberli, 2006: Distributed glacier mass-balance modelling as an important component of modern multi-level glacier monitoring. Ann. Glaciol., 43, 335343, https://doi.org/10.3189/172756406781812285.

Maraun, D., 2012: Nonstationarities of regional climate model biases in European seasonal mean temperature and precipitation sums. Geophys. Res. Lett., 39, L06706, https:// doi.org/10.1029/2012GL051210.

McGuffie, K., and A. Henderson-Sellers, 2005: A Climate Modelling Primer. Wiley, 296 pp.

Mendoza, P. A., and Coauthors, 2015: Effects of hydrologic model choice and calibration on the portrayal of climate change impacts. J. Hydrometeor., 16, 762-780, https://doi.org/10.1175/ JHM-D-14-0104.1.

Minville, M., D. Cartier, C. Guay, L.-A. Leclaire, C. Audet, S. Le Digabel, and J. Merleau, 2014: Improving process representation in conceptual hydrological model calibration using climate simulations. Water Resour. Res., 50, 5044-5073, https:// doi.org/10.1002/2013WR013857.

Monteith, J. L., 1965: Evaporation and the environment. The State and Movement of Water in Living Organisms, G. E. Fogg, Ed., Symposia of the Society for Experimental Biology, No. 19, Cambridge University Press, 205-234.

Music, B., and D. Caya, 2007: Evaluation of the hydrological cycle over the Mississippi River basin as simulated by the Canadian Regional Climate Model (CRCM). J. Hydrometeor., 8, 969-988, https://doi.org/10.1175/JHM627.1.

Najafi, M. R., H. Moradkhani, and I. W. Jung, 2011: Assessing the uncertainties of hydrologic model selection in climate change impact studies. Hydrol. Processes, 25, 2814-2826, https:// doi.org/10.1002/hyp.8043.

Oudin, L., F. Hervieu, C. Michel, C. Perrin, V. Andréassian, F. Anctil, and C. Loumagne, 2005: Which potential evapotranspiration input for a lumped rainfall-runoff model? Part 2-Towards a simple and efficient potential evapotranspiration model for rainfall-runoff modelling. J. Hydrol., 303, 290-306, https://doi.org/ 10.1016/j.jhydrol.2004.08.026.

Peixoto, J. P., and A. H. Oort, 1992: Physics of Climate. American Institute of Physics, 520 pp.

Pellicciotti, F., B. Brock, U. Strasser, P. Burlando, M. Funk, and J. Corripio, 2005: An enhanced temperature-index glacier melt model including the shortwave radiation balance: Development and testing for Haut Glacier d'Arolla, Switzerland. J. Glaciol., 51, 573-587, https://doi.org/10.3189/172756505781829124.

Perrin, C., C. Michel, and V. Andréassian, 2003: Improvement of a parsimonious model for streamflow simulation. J. Hydrol., 279, 275-289, https://doi.org/10.1016/S0022-1694(03)00225-7. 
Plummer, D. A., and Coauthors, 2006: Climate and climate change over North America as simulated by the Canadian RCM. J. Climate, 19, 3112-3132, https://doi.org/10.1175/JCLI3769.1.

Poulin, A., F. Brissette, R. Leconte, R. Arsenault, and J. S. Malo, 2011: Uncertainty of hydrological modelling in climate change impact studies in a Canadian, snow-dominated river basin. J. Hydrol., 409, 626-636, https://doi.org/10.1016/j.jhydrol.2011.08.057.

Priestley, C. H. B., and R. J. Taylor, 1972: On the assessment of surface heat fluxes and evaporation using large-scale parameters. Mon. Wea. Rev., 100, 81-92, https://doi.org/10.1175/ 1520-0493(1972)100<0081:OTAOSH >2.3.CO;2.

Prudhomme, C., and H. Davies, 2009a: Assessing uncertainties in climate change impact analyses on the river flow regimes in the UK. Part 1: Baseline climate. Climatic Change, 93, 177-195, https://doi.org/10.1007/s10584-008-9464-3.

$\longrightarrow$, and 2009b: Assessing uncertainties in climate change impact analyses on the river flow regimes in the UK. Part 2: Future climate. Climatic Change, 93, 197-222, https://doi.org/ 10.1007/s10584-008-9461-6.

Renard, B., D. Kavetski, G. Kuczera, M. Thyer, and S. W. Franks, 2010: Understanding predictive uncertainty in hydrologic modeling: The challenge of identifying input and structural errors. Water Resour. Res., 46, W05521, https://doi.org/ 10.1029/2009WR008328.

Roberts, J., and K. Snelgrove, 2015: Uncertainty in regional climate model mean runoff projections under climate change: Case study of Labrador's Churchill River basin. Atmos.-Ocean, 53, 319-331, https://doi.org/10.1080/07055900.2015.1026872.

Seaby, L. P., J. C. Refsgaard, T. O. Sonnenborg, and A. L. Højberg, 2015: Spatial uncertainty in bias corrected climate change projections and hydrogeological impacts. Hydrol. Processes, 29, 4514-4532, https://doi.org/10.1002/hyp.10501.

Seiller, G., and F. Anctil, 2014: Climate change impacts on the hydrologic regime of a Canadian river: Comparing uncertainties arising from climate natural variability and lumped hydrological model structures. Hydrol. Earth Syst. Sci., 18, 2033-2047, https://doi.org/10.5194/hess-18-2033-2014.

Sudheer, K. P., G. Lakshmi, and I. Chaubey, 2011: Application of a pseudo simulator to evaluate the sensitivity of parameters in complex watershed models. Environ. Modell. Software, 26, 135-143, https://doi.org/10.1016/j.envsoft.2010.07.007.

Supharatid, S., 2015: Assessment of CMIP3-CMIP5 climate models precipitation projection and implication of flood vulnerability of Bangkok. Amer. J. Climate Change, 4, 55112, https:// doi.org/10.4236/ajcc.2015.41011.

Tebaldi, C., R. L. Smith, D. Nychka, and L. O. Mearns, 2005: Quantifying uncertainty in projections of regional climate change: A Bayesian approach to the analysis of multimodel ensembles. J. Climate, 18, 1524-1540, https://doi.org/10.1175/JCLI3363.1.

Thompson, D. W. J., E. A. Barnes, C. Deser, W. E. Foust, and A. S. Phillips, 2015: Quantifying the role of internal climate variability in future climate trends. J. Climate, 28, 6443-6456, https://doi.org/10.1175/JCLI-D-14-00830.1.

Troin, M., J. A. Velázquez, D. Caya, and F. Brissette, 2015a: Comparing statistical post-processing of regional and global climate scenarios for hydrological impacts assessment: A case study of two Canadian catchments. J. Hydrol., 520, 268-288, https://doi.org/10.1016/j.jhydrol.2014.11.047.

, R. Arsenault, and F. Brissette, 2015b: Performance and uncertainty evaluation of snow models on snowmelt flow simulations over a Nordic catchment (Mistassibi, Canada). Hydrology, 2, 289-317, https://doi.org/10.3390/hydrology2040289.

_ A. Poulin, M. Baraer, and F. Brissette, 2016: Comparing snow models under current and future climates: Uncertainties and implications for hydrological impact studies. J. Hydrol., 540, 588-602, https://doi.org/10.1016/j.jhydrol.2016.06.055.

Turcotte, R., L. G. Fortin, V. Fortin, J. P. Fortin, and J. P. Villeneuve, 2007: Operational analysis of the spatial distribution and the temporal evolution of the snowpack water equivalent in southern Québec, Canada. Nord. Hydrol., $\mathbf{3 8}$, 211-234, https://doi.org/10.2166/nh.2007.009.

Valéry, A., 2010: Modélisation précipitations-Débit sous influence nivale. Élaboration d'un module neige et évaluation sur 380 bassins versants. Ph.D. thesis, Agro Paris Tech, 417 pp., https://webgr.irstea.fr/wp-content/uploads/2012/ 07/2010-VALERY-THESE.pdf.

Van Griensven, A., T. Meixner, R. Srinivasan, and S. Grunwald, 2008: Fit-for-purpose analysis of uncertainty using splitsampling evaluations. Hydrol. Sci. J., 53, 1090-1103, https:// doi.org/10.1623/hysj.53.5.1090.

Vano, J. A., J. B. Kim, D. E. Rupp, and P. W. Mote, 2015: Selecting climate change scenarios using impact-relevant sensitivities. Geophys. Res. Lett., 42, 5516-5525, https://doi.org/10.1002/2015GL063208.

Vehviläinen, B., 1992: Snow cover models in operational watershed forecasting. Ph.D. dissertation, Finnish Environment Institute, $112 \mathrm{pp}$.

Velázquez, J. A., F. Anctil, M. H. Ramos, and C. Perrin, 2011: Can a multi-model approach improve hydrological ensemble forecasting? A study on 29 French catchments using 16 hydrological model structures. Adv. Geosci., 29, 33-42, https:// doi.org/10.5194/adgeo-29-33-2011.

— M. Troin, and D. Caya, 2015a: Modelación hidrológica del río Tampaón en el contexto del cambio climático. Tecnol. Cienc. Agua, 6 (5), 17-30.

,,--- , and F. Brissette, 2015b: Evaluating the timeinvariance hypothesis of climate model bias correction: Implications for hydrological impact studies. J. Hydrometeor., 16, 2013-2026, https://doi.org/10.1175/JHM-D-14-0159.1.

Verseghy, D. L., 1991: CLASS-A Canadian Land Surface Scheme for GCMS. I. Soil model. Int. J. Climatol., 11, 111-113, https:// doi.org/10.1002/joc.3370110202.

_ , N. A. McFarlane, and M. Lazare, 1993: CLASS-A Canadian Land Surface Scheme for GCMs. II. Vegetation model and coupled runs. Int. J. Climatol., 13, 347-370, https://doi.org/ 10.1002/joc.3370130402.

von Storch, H., and F. W. Zwiers, 1999: Statistical Analysis in Climate Research. Cambridge University Press, 484 pp.

Wagener, T., and H. V. Gupta, 2005: Model identification for hydrological forecasting under uncertainty. Stochastic Environ. Res. Risk Assess., 19, 378-387, https://doi.org/10.1007/s00477-005-0006-5.

Wilby, R. L., 2005: Uncertainty in water resource model parameters used for climate change impact assessment. Hydrol. Processes, 19, 3201-3219, https://doi.org/10.1002/hyp.5819.

— , and I. Harris, 2006: A framework for assessing uncertainties in climate change impacts: Low-flow scenarios for the River Thames, UK. Water Resour. Res., 42, W02419, https://doi.org/ 10.1029/2005WR004065.

Woldemeskel, F. M., A. Sharma, B. Sivakumar, and R. Mehrotra, 2016: Quantification of precipitation and temperature uncertainties simulated by CMIP3 and CMIP5 models. J. Geophys. Res. Atmos., 121, 3-17, https://doi.org/10.1002/2015JD023719. 